\title{
Rod Photoreceptors Signal Fast Changes in Daylight Levels Using a Cx36-Independent Retinal Pathway in Mouse
}

\author{
Rose Pasquale, ${ }^{\star}$ Yumiko Umino, ${ }^{*}$ and Eduardo Solessio \\ Center for Vision Research, Department of Ophthalmology, SUNY Upstate Medical University, Syracuse, New York 13210
}

Temporal contrast detected by rod photoreceptors is channeled into multiple retinal rod pathways that ultimately connect to cone photoreceptor pathways via Cx36 gap junctions or via chemical synapses. However, we do not yet understand how the different rod pathways contribute to the perception of temporal contrast (changes in luminance with time) at mesopic light levels, where both rods and cones actively respond to light. Here, we use a forced-choice, operant behavior assay to investigate rod-driven, temporal contrast sensitivity (TCS) in mice of either sex. Transgenic mice with desensitized cones (GNAT2 ${ }^{\text {cpfls }}$ line) were used to identify rod contributions to TCS in mesopic lights. We found that at low mesopic lights ( 400 photons $/ \mathrm{s} / \mu \mathrm{m}^{2}$ at the retina), control and GNAT2 ${ }^{\text {cpfl3 }}$ mice had similar TCS. Surprisingly, at upper mesopic lights $\left(8000\right.$ photons $\left./ \mathrm{s} / \mu \mathrm{m}^{2}\right)$, GNAT2 ${ }^{c p f l 3}$ mice exhibited a relative reduction in TCS to low $(<12 \mathrm{~Hz})$ while maintaining normal TCS to high $(12-36 \mathrm{~Hz})$ temporal frequencies. The rod-driven responses to high temporal frequencies developed gradually over time $(>30 \mathrm{~min})$. Furthermore, the TCS of GNAT2 ${ }^{c f f l}$ and GNAT2 $2^{c f f l}:: \mathrm{Cx} 36^{-1-}$ mice matched closely, indicating that transmission of high-frequency signals (1) does not require the rod-cone Cx36 gap junctions as has been proposed in the past; and (2) a Cx36-independent rod pathway(s) (e.g., direct rod to OFF cone bipolar cell synapses and/or glycinergic synapses from AII amacrine cells to OFF ganglion cells) is sufficient for fast, mesopic rod-driven vision. These findings extend our understanding of the link between visual circuits and perception in mouse.

Key words: gap junctions; mesopic vision; mouse vision; operant behavior; rod pathways; temporal contrast sensitivity

Significance Statement

The contributions of specific retinal pathways to visual perception are not well understood. We found that the temporal processing properties of rod-driven vision in mice change significantly with light level. In dim lights, rods relay relatively slow temporal variations. However, in daylight conditions, rod pathways exhibit high sensitivity to fast but not to slow temporal variations, whereas cone-driven responses supplement the loss in rod-driven sensitivity to slow temporal variations. Our findings highlight the dynamic interplay of rod- and cone-driven vision as light levels rise from night to daytime levels. Furthermore, the fast, rod-driven signals do not require the rod-to-cone Cx36 gap junctions as proposed in the past, but rather, can be relayed by alternative Cx36-independent rod pathways.

\section{Introduction}

The speed of the visual responses mediated by the rod system depends on the level of background illumination (Sharpe et al., 1989). Human rods can detect flicker up to $15 \mathrm{~Hz}$ in $\mathrm{dim}$ (sco-

\footnotetext{
Received Feb. 26, 2019; revised Nov. 11, 2019; accepted Nov. 17, 2019.

Author contributions: R.P., Y.U., and E.S. designed research; R.P. and Y.U. performed research; R.P., Y.U., and E.S. analyzed data; R.P., Y.U., and E.S. wrote the paper.

This work was supported by the National Institutes of Health Grant R01 EY026216, the Department of Ophthalmology, State University of New York Upstate Medical University, an unrestricted Grant from Research to Prevent Blindness, and the Lions of Central New York. We thank Dr. Dale Hunter and Dr. Christophe Ribelayga for insightful comments on an earlier version of the paper.

The authors declare no competing financial interests.

*R.P. and Y.U. contributed equally to this work.

Correspondence should be addressed to Eduardo Solessio at solessie@upstate.edu.

https://doi.org/10.1523/JNEUROSCI.0455-19.2019

Copyright $\odot 2020$ the authors
}

topic) light conditions, but rod-driven vision extends to $28 \mathrm{~Hz}$ as light levels rise through the mesopic range (Conner and MacLeod, 1977; Conner, 1982; Hess and Nordby, 1986). One hypothesis underlying the duality of rod-mediated flicker perception is the routing of rod signals over multiple retinal circuits (for review, see Sharpe and Stockman, 1999; Bloomfield and Dacheux, 2001; Bloomfield and Völgyi, 2009; Grimes et al., 2018a). Dim rod signals are relayed largely along the highly sensitive primary pathway to rod bipolar cells and then to amacrine AII cells, where they are differentially transmitted via Cx36 gap junctions to $\mathrm{ON}$ cone bipolar cells and via glycinergic synapses to OFF cone bipolar cells (for review, see Bloomfield and Dacheux, 2001; Grimes et al., 2018a).

As light levels rise and rod vision speeds up, rod signals are thought to be transmitted by the secondary rod pathway to cones 


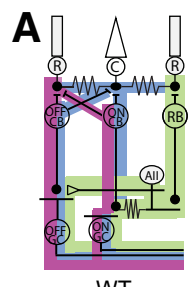

WT

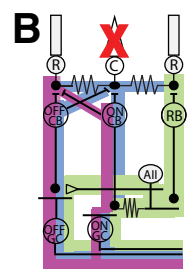

$\mathrm{G} 2(\mathrm{cpfl3}$ or KO)

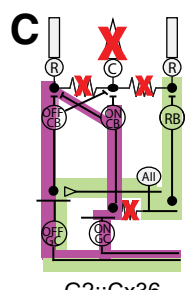

$\mathrm{G} 2:: \mathrm{C} \times 36$

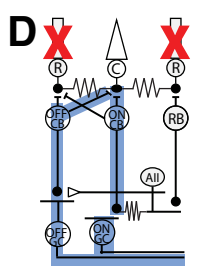

G1
Figure 1. Rod circuit schematics of control and transgenic mice. $\boldsymbol{A}-\boldsymbol{E}$, Circuit diagrams depicting WT $(\boldsymbol{A})$ and targets of disruption in transgenic mice $(\boldsymbol{B}-\boldsymbol{E})$. $\boldsymbol{B}, \mathrm{G} 2$ mice (cpfl3 and K0) have disrupted cone circuits leaving only functional rod circuits. $\boldsymbol{C}, \mathrm{G} 2:: \mathrm{C} \times 36$ mice have both disrupted cone circuits and disrupted $\mathrm{C} \times 36$-dependent rod pathways (secondary pathway and ON branch of the primary pathway). $\boldsymbol{D}, \mathrm{G} 1$ mice have disrupted rod circuits leaving only functional cone circuits. $\boldsymbol{E}, \mathrm{G} 1:: \mathrm{G} 2 \mathrm{mice}$ have disrupted rod and cone circuits. R, rod; C cone; black resistors, Cx36 gap junctions; RB, rod bipolar; All, amacrine All; ON CB, ON cone bipolar; OFF CB OFF cone bipolar; GC ganglion cell; green, primary path circuit; blue, secondary path and cone path circuit; pink, tertiary path circuit.

via $\mathrm{Cx} 36$ gap junctions (Cx36-dependent rod pathways) and are then relayed to cone bipolar cells (Nelson, 1977; Schneeweis and Schnapf, 1999; Deans et al., 2002; Abd-El-Barr et al., 2009; O'Brien et al., 2012). However, in mouse the coupling strength of rod-cone Cx36 gap junctions decreases significantly following prolonged exposure to light (Ribelayga et al., 2008; O'Brien et al., 2012; Li et al., 2013; O'Brien, 2014; Jin et al., 2015; Zhang et al., 2015), potentially attenuating the contribution of these pathways to temporal sensitivity under mesopic conditions. Alternatively, fast rod signals may be transmitted by the tertiary rod pathway via direct synaptic contacts largely to cone OFF bipolar cells (DeVries and Baylor, 1995; Soucy et al., 1998; Hack et al., 1999; Tsukamoto et al., 2001, 2007; Field and Rieke, 2002; Li et al., 2010; Pang et al., 2010, 2012; Lei, 2012; Tsukamoto and Omi, 2014; Cowan et al., 2016). A final alternative route for fast rod signals in mesopic lights follows from recent electrophysiological evidence in mouse and primate showing that the primary (or dominant) pathway can respond to relatively fast (up to $16 \mathrm{~Hz}$ ) temporal variations at irradiance levels of up to $250-300 \mathrm{R} * / \mathrm{rod} / \mathrm{s}$ (Ke et al., 2014; Grimes et al., 2018b). Although the relative contributions of these pathways (or particular branches of these pathways) to temporal vision in the mesopic range is unclear, it is likely to be dependent on mean illumination level and temporal properties of the stimulus.

Mouse rods have been shown to signal incremental flashes at irradiance levels of up to $10^{4}-10^{5} \mathrm{R}^{\star} / \mathrm{rod} / \mathrm{s}$ after prolonged adaptation (Yin et al., 2006; Altimus et al., 2010; Naarendorp et al., 2010; Tikidji-Hamburyan et al., 2017), yet the contribution of rods to perceptual temporal contrast sensitivity (TCS) under such bright conditions and which rod pathway(s) relay these signals are not known. Here, we investigated the properties of roddriven mesopic TCS using the GNAT2 ${ }^{c p f l 3}$ mouse model (Chang et al., 2006) to isolate rod responses and a forced-choice operant behavior assay developed in our laboratory (Umino et al., 2018, 2019). Following the validation of GNAT2 $2^{c p f l 3}$ mice for this study, we address four questions related to rod-driven vision: (1) how does rod-driven TCS in GNAT2 ${ }^{c p f l 3}$ mice change as light levels rise through the mesopic range, (2) how does TCS develop during prolonged periods of light adaptation, (3) is the secondary rod pathway required to mediate the response to fast variations in mesopic lights, and (4) what are the irradiance levels that delimit the mesopic irradiance range in mice?

\section{Materials and Methods}

Animal strains. All procedures were approved by the Institutional Animal Care and Use Committee at SUNY Upstate Medical University and were

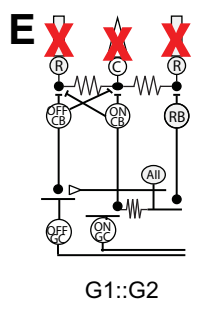

in compliance with both the Guide for the Care and Use of Laboratory Animals and the Association for Research in Vision and Ophthalmology Statement for the Use of Animals in Ophthalmic and Vision Research. The following strains of adult mice (3-6 months of age, male and female) were used and maintained on a C57BL/6J background (WT; The Jackson Laboratory), $\mathrm{Cx} 36^{-1-}$ (Cx36; Güldenagel et al., 2001), GNAT1 ${ }^{-1-}$ (G1; Calvert et al., 2000), GNAT2 ${ }^{\text {cpfl3/cpfl3 }}$ (G2; Chang et al., 2006), GNAT2 ${ }^{-1-}$ (G2KO; Ronning et al., 2018, provided by M. Burns, UC Davis), GNAT1 $^{-1-}::$ GNAT2 ${ }^{\text {cpfl3/cpfl3 }}$ (G1::G2; crossed in our laboratory), and GNAT2 ${ }^{\mathrm{Cpfl}^{3} / \mathrm{cpfl}^{3}:}$ $\mathrm{C} \times 36^{-1-}$ (G2::Cx36; crossed in our laboratory). Figure 1 shows the retina routing schematics for the mouse lines listed above. Mice were maintained on a 14/10 h light/dark cycle at SUNY Upstate Medical University. With the exception of mice used for operant behavior experiments (see Operant behavior assay), all mice were provided food and water ad libitum.

Operant behavior assay. To determine TCS of control and transgenic mice, we used an operant behavior assay, as described previously (Umino et al., 2018,2019). Briefly, mice are trained to detect and indicate whether an overhead light stimulus is flickering or not flickering. This is a forcedchoice visual task that requires cortical input and resultant decisionmaking. To provide motivation to learn and perform the task, mice are maintained on a food restriction schedule (85-90\% expected body weight). The operant behavior chamber (Lafayette Instruments) is equipped with a custom-built overhead programmable LED-based light stimulus (505 or $405 \mathrm{~nm}$ central emission), a reward tray, and two nosepoke ports on the opposite wall of the chamber to indicate response. Following a heads-up tone, the mouse starts a trial with a visit to the reward tray. The mouse is presented with an overhead light stimulus (flicker or no flicker) along with a cueing tone indicating that the trial is under way. The mouse responds by visiting the corresponding left (flicker) or right (no flicker) nose-poke port on the opposite wall and returns to the reward tray for positive reinforcement. All responses are recorded automatically using ABET II Standard software (Lafayette Instruments) and compiled at the end of each session as the following output variables: Hit (correctly report presence of flicker), False Alarms (report flicker when no flicker presented), Miss (report no flicker when flicker presented), and Correct Rejection (correctly report presence of no flicker). Training mice to learn and perform this task reproducibly takes $\sim 1$ month.

To obtain a measure of sensitivity that is independent of daily response bias and motivation, we apply the theory of signal detection (TSD). TSD is commonly used in psychophysical studies of sensory systems (Macmillan and Creelman, 2005) and is applicable to our behavior assay (Umino et al., 2018). TSD defines a discriminability factor, $d^{\prime}$, which provides a bias-free measure of flicker sensitivity in mouse (Umino et al., 2018). Hit versus False Alarm pairs cluster along the receiver operating characteristic curve defined by $d^{\prime}$.

To determine TCS, we first measured the psychometric functions (plots of the sensitivity index, $d^{\prime}$, in response to different contrast levels) at a set temporal frequency and mean illumination. In each daily session mice were first tested with a corrective protocol of $\sim 300$ trials at a constant contrast adjusted to elicit $d^{\prime}$ values of $\sim 2$. After completing the corrective protocol ( $\sim 30-40 \mathrm{~min})$, mice ran a testing protocol (typically $400-500$ trials, $1-2 \mathrm{~h}$ ) in which the contrast was randomly varied (5-6 different contrast conditions in $5 \%$ increments). To generate the psychometric functions we calculated and plotted the values of $d^{\prime}$ for each contrast. Because the psychometric functions are approximately linear with contrast (Umino et al., 2018) we fit the data with a regression line. We repeatedly measured and averaged the psychometric functions until the cumulative value of the correlation factor $R^{2}$ was 0.75 or higher; a process that often required averaging two or three psychometric functions. We then determined the contrast threshold as the contrast at the 
Table 1. Pupil area and retinal irradiance values of WT and transgenic mice

\begin{tabular}{|c|c|c|c|c|c|c|c|c|c|c|}
\hline \multirow[t]{2}{*}{ Corneal irradiance, $\mathrm{ph} / \mathrm{s} / \mathrm{m}^{2}$} & \multicolumn{5}{|c|}{ Pupil area, $\mathrm{mm}^{2}$} & \multicolumn{5}{|c|}{ Retinal irradiance, $\mathrm{ph} / \mathrm{s} / \mu \mathrm{m}^{2}\left(\mathrm{R}^{*} / \mathrm{rod} / \mathrm{s}\right) \dagger$} \\
\hline & $\begin{array}{l}\text { WT } \\
(n=5-7)\end{array}$ & $\begin{array}{l}\text { G2 cpfl3 } \\
(n=5-7)\end{array}$ & $\begin{array}{l}\mathrm{G} 2 \mathrm{KO} \\
(n=4)\end{array}$ & $\begin{array}{l}\mathrm{G} 2: \mathrm{C} \times 36 \\
(n=5)\end{array}$ & $\begin{array}{l}\mathrm{G} 1 \\
(n=4-7)\end{array}$ & WT & G2 cpfl3 & G2 KO & $\mathrm{G} 2: \mathrm{C} \times 36$ & G1 \\
\hline \multicolumn{11}{|l|}{$505 \mathrm{~nm}$} \\
\hline $1.5 \mathrm{E} 19$ & 0.040 & 0.047 & NA & 0.035 & 0.058 & $33,069(28,770)$ & $38,856(33,804)$ & NA & $28,935(25,174)$ & $47,950(41,716)$ \\
\hline 6.7E18 & 0.060 & 0.052 & NA & 0.049 & 0.088 & $22,321(19,419)$ & $19,345(16,830)$ & NA & $18,229(15,859)$ & $32,738(28,482)$ \\
\hline $4.6 \mathrm{E} 17$ & 0.25 & 0.35 & 0.37 & 0.31 & 0.51 & $6,386(5,556)$ & $8,940(7,779)$ & $9,451(8,223)$ & $7,919(6,890)$ & $13,028(11,335)$ \\
\hline $4.8 \mathrm{E} 16$ & 0.96 & 1.51 & 1.26 & 1.46 & 1.92 & $2,555(2,223)$ & $4,019(3,497)$ & $3,354(2,918)$ & $3,886(3,381)$ & $5,111(4,447)$ \\
\hline 5.0E15 & 1.30 & 1.73 & 1.67 & 2.43 & 3.42 & 361 (314) & 480 (418) & 464 (404) & 675 (587) & 950 (827) \\
\hline $5.2 \mathrm{E} 14$ & 2.01 & 2.46 & NA & 3.19 & 3.51 & $58(51)$ & $71.2(62)$ & NA & $92(80)$ & $102(88)$ \\
\hline $5.4 \mathrm{E} 13$ & 2.83 & 2.89 & NA & 3.36 & 3.02 & $8(7)$ & $9(8)$ & NA & $10(9)$ & $9(8)$ \\
\hline Dark & 3.76 & 3.36 & NA & 3.78 & 3.31 & NA & NA & NA & NA & NA \\
\hline \multicolumn{11}{|l|}{$405 \mathrm{~nm}$} \\
\hline $4.0 \mathrm{E} 17$ & 0.22 & NA & NA & NA & NA & $4,943(1,074)$ & NA & NA & NA & NA \\
\hline $2.3 \mathrm{E} 17$ & 0.29 & NA & NA & NA & NA & 3,727 (811) & NA & NA & NA & NA \\
\hline $2.3 \mathrm{E} 16$ & 1.09 & NA & NA & NA & NA & 1,393 (303) & NA & NA & NA & NA \\
\hline
\end{tabular}

Pupil area and retinal irradiance values over a range of corneal irradiance intensities. Data reported as the mean. For retinal irradiance, we also indicate, in parentheses, $R * /$ rod/s values for reference (tinitial: uncorrected for bleaching effects). See Materials and Methods for details of the calculations used to convert irradiance to photoisomerization rates. NA, Not applicable.

intersection point between the linear interpolation and the line for $d^{\prime}=$ 1 ( $\sim 70 \%$ correct response). We defined contrast sensitivity as the inverse of the contrast threshold. Measurements were repeated at multiple frequencies and mean illumination levels to produce TCS functions (TCSFs) for mice.

Determination of retinal irradiance. Retinal irradiance of WT, G2, G2:: Cx36, and G1 mice was determined as described previously (Umino et al., 2018, 2019). Briefly, values of corneal irradiance were measured with an M370 Optometer (Graseby Optronics) placed in the position of the cornea of the mice and directed toward the side panels of the chamber. The corresponding steady-state pupil areas of freely behaving mice in the operant chamber were determined as described by Bushnell et al. (2016) and the values are listed in Table 1. The values of corneal irradiance and pupil areas were used to estimate retinal irradiance using the approach described by Lyubarsky et al. (2004) and Umino et al. (2019) (Table 1 lists the pupil areas and corresponding retinal irradiance values for each mouse line used in this study). The differences in pupil area and retinal irradiance values for WT, and G2 mice were relatively small; therefore, for practical purposes, we assumed that the irradiance values were the same for these mice. A similar argument applied to the retinal irradiance values of $\mathrm{G} 2$ and $\mathrm{G} 2:: \mathrm{Cx} 36$ mice. In contrast, the differences in pupil area and retinal irradiance values for WT and G1 mice were substantial and indicated in the corresponding figures. Note that in our behavioral experiments we express retinal irradiance in terms of photon flux at the retina $\left(\mathrm{ph} / \mathrm{s} / \mu \mathrm{m}^{2}\right)$ rather than in photoisomerizations/rod/s because the prolonged exposure to high irradiance levels used in the operant behavior experiments are likely to have bleaching effects that will change the effective collecting area of rod photoreceptors. For reference purposes, Table 1 also shows the corresponding photoisomerization rates $\left(\mathrm{R}^{\star} /\right.$ $\mathrm{rod} / \mathrm{s}$ ) at $505 \mathrm{~nm}$ (Lyubarsky et al., 2004), uncorrected for bleaching effects and calculated as shown in the next section.

Estimation of photoisomerization rates in rods and cones. To estimate the photoisomerization rates of rods and "pure" $\mathrm{M}$ - and S-opsincontaining cones in response to 405 and $505 \mathrm{~nm}$ stimuli we applied the following formulas (Lyubarsky et al., 2004):

$$
\theta(\lambda)=Q(\lambda) \tau(\lambda) \frac{A_{\text {pupil }}}{A_{\text {retina }}} a_{c}(\lambda)
$$

and

$$
a_{c}(\lambda)=f \pi \frac{d^{2}}{4}\left[1-10^{-\Delta D(\lambda) L}\right] \gamma
$$

Where $\theta(\lambda)$ is the photoisomerization rate, $Q(\lambda)$ is corneal irradiance, $\tau(\lambda)$ is media loss, $A_{\text {pupil }}$ is the pupil area as a function of illumination level, $A_{\text {retina }}=18 \mathrm{~mm}^{2}$ (Lyubarsky et al., 2004), and $a_{c}(\lambda)$ is the end-on collecting area at the retina. To calculate $a_{c}(\lambda)$ we adopt the parameter values estimated by Lyubarsky et al. (2004): light funneling by the inner segment $f=1.3$, quantal efficiency $\gamma=0.63$, outer segment length of photoreceptors $L=13 \mu \mathrm{m}$ for cones and $L=25 \mu \mathrm{m}$ for rods, specific axial density $\Delta D\left(\lambda_{\text {Max }}\right)=0.018 \mathrm{od} / \mu \mathrm{m}$. The accepted values for end-on collecting areas in rods and pure cones at the wavelengths of maximal sensitivity are, for rods, $a_{c R}(498 \mathrm{~nm})=0.87 \mu \mathrm{m}^{2}$ (Lyubarsky et al., 2004) and for pure M-cones, $a_{c M}(505 \mathrm{~nm})=1.0 \mu \mathrm{m}^{2}$ (Naarendorp et al., 2010). We adopt a similar value for pure S-cones $a_{c S}(365 \mathrm{~nm})=1.0 \mu \mathrm{m}^{2}$. With knowledge of $a_{c}\left(\lambda_{\mathrm{Max}}\right)$ we derive the value of $a_{c}(\lambda)$ at other wavelengths using the relation:

$$
a_{c}(\lambda)=\frac{\left[1-10^{-\Delta D(\lambda) L}\right]}{\left[1-10^{-\Delta D\left(\lambda_{\max }\right)}\right]} a_{c}\left(\lambda_{\max }\right),
$$

where

$$
\Delta D(\lambda)=\Delta D\left(\lambda_{\max }\right)^{*} R S(\lambda)
$$

and $R S(\lambda)$ is the relative sensitivity for each pigment calculated from the respective opsin nomograms (Govardovskii et al., 2000) and media losses (Jacobs and Williams, 2007) using the rodent $\alpha$-optics toolbox (Lucas et al., 2014). We applied equation (3) to calculate the values for the end-on collecting areas at the stimulus wavelengths of 405 and $505 \mathrm{~nm}: a_{c R}(405$ $\mathrm{nm})=0.27 \mu \mathrm{m}^{2}, a_{c R}(505 \mathrm{~nm})=0.86 \mu \mathrm{m}^{2}, a_{c M}(405 \mathrm{~nm})=0.24 \mu \mathrm{m}^{2}$, $a_{c M}(505 \mathrm{~nm})=1.0 \mu \mathrm{m}^{2}, a_{c S}(405 \mathrm{~nm})=0.14 \mu \mathrm{m}^{2}$, and $a_{c S}(505 \mathrm{~nm})=$ $10^{-6} \mu \mathrm{m}^{2}$.

Electroretinograms. Mice were dark-adapted overnight and all procedures were performed under dim red light. Mice were anesthetized by intraperitoneal injection of a ketamine/xylazine mixture (90 and $9 \mathrm{mg} /$ $\mathrm{kg}$, respectively), and their pupils dilated with a drop of $1 \%$ tropicamide. The anesthetized mice were then placed on a heating pad $\left(37^{\circ} \mathrm{C}\right)$ inside a Ganzfeld ColorDome stimulator (Diagnosys, Espion $E^{2}$ system). Reference and ground electrodes were placed in the mouth and intradermally next to the tail, respectively. A drop of $2.5 \%$ hypromellose GONAK solution (AKORN) was applied to the eye and gold loop electrodes were placed on the cornea under infrared illumination. After completing the setup procedure mice were dark-adapted for $10 \mathrm{~min}$ before the start of recordings. Flash ERGs were elicited with $4 \mathrm{~ms}$ green $(500 \mathrm{~nm})$ flashes ranging from ( -3 to $\left.5 \log \mathrm{R}^{\star} / \mathrm{rod}\right)$. Flicker ERGs were elicited by a sinusoidal stimulus ( $100 \%$ contrast) at varying mean luminance $(-1$ to $5.5 \log \mathrm{R}^{\star} / \mathrm{rod} / \mathrm{s}$ ) and temporal frequencies. Stimulus intensities were converted to rod photoisomerization rates using the conversion factor as defined by Lyubarsky et al., 2004 (their Eq. 10).

The b-wave response amplitudes were measured as the difference in amplitude from the a-wave trough to the b-wave peak using Diagnosys software tools and data analyzed with SigmaPlot software (Systat Software). Flicker ERG data were analyzed by Fourier transformation and the magnitude of the fundamental component plotted as a function of background intensity. 
Optomotor responses. Optomotor contrast sensitivity of mice was measured by observing optomotor reflex behavior using a two-alternative forced choice protocol in combination with the OptoMotory apparatus (Prusky et al., 2004) as described previously (Umino et al., 2008). Briefly, dark-adapted mice were placed on a pedestal located at the center of an enclosure formed by four computer monitors that display the virtual stimulus gratings. The optomotor stimulus consisted of vertically oriented, sinusoidal patterns rotating in the clockwise or counter-clockwise direction as selected randomly by the computer-controlled protocol before the start of a trial. Trial durations were $5 \mathrm{~s}$. Head movements of mice were monitored by an observer using infrared illumination and a video camera positioned above the animal. The observer selected the direction of rotation based on the mouse movements unaware of the direction that the pattern rotated during the trials. Auditory feedback indicated to the observer whether the selected direction was correct or incorrect. A computer program controlled the contrast of the stimulus following a staircase paradigm (Umino et al., 2006) that converged to a threshold value arbitrarily defined as 70\% correct responses (Prusky et al., 2004). Contrast sensitivity was defined as the reciprocal of the threshold value. Sensitivity for each mouse was estimated as the average of four independent trials. Results from trials differing by $>2$ SD from the average were discarded. Spatial and temporal frequencies of the stimulus grating are indicated in the text. Luminance within the OptoMotry enclosure was attenuated with neutral density filters (Lee Filters) positioned between the computer monitors and the mice. Light calibrations were performed as described previously (Umino et al., 2008).

Tissue preparation and immunohistochemistry. Eyecups were fixed for $15 \mathrm{~min}$ in $4 \%$ paraformaldehyde ( $1 \%$ for $\mathrm{Cx} 36$ antibody) diluted in $0.1 \mathrm{M}$ phosphate buffer, pH 7.4 (PB). After fixation, eyecups were washed in $\mathrm{PB}$ and cryoprotected with a sucrose gradient $(15,20$, and $30 \%)$. They were then embedded in Tissue-Tek OCT medium (Sakura), frozen on dry ice, and cryosectioned at $16 \mu \mathrm{m}$. Sections were blocked with a solution of $10 \%$ normal donkey serum in PBS $+0.3 \%$ Triton X-100 at room temperature for $1 \mathrm{~h}$. They were then incubated with primary antibodies diluted in blocking medium at room temperature overnight. Next, sections were washed in PBS and incubated with secondary antibodies diluted in blocking medium at room temperature for $2 \mathrm{~h}$, washed in PBS, and mounted with ProLong Diamond Antifade Mountant (Life Technologies). An LSM780 confocal microscope was used to image $2-3$ sections in 2-3 animals for each antibody combination.

Antibodies. The following primary antibodies were used: mouse antiCx36 (Cx36;1:100; Invitrogen, catalog \#36-4600; RRID:AB_2314259), rabbit anti-cone arrestin (CAR;1:2500; gift from Dr. Cheryl Craft, University of Southern California; Zhu et al., 2002), rabbit anti-calbindin D28K (Calb;1:2000; Swant, catalog \#CB 38; RRID:AB_10000340), rabbit anti-PKC $\alpha$ (1:3000; Santa Cruz Biotechnology, catalog \#sc-208; RRID: AB_2168668), mouse anti-CtBP2 (1:2000; BD Biosciences, catalog \#612044; RRID:AB_399431), and biotinylated peanut agglutinin (PNA; 1:500; Vector Laboratories, catalog \#B-1075; RRID:AB_2313597). The following secondary antibodies were used: (Cx36)TRITC goat antimouse (1:400; Jackson ImmunoResearch Laboratories, catalog \#115025-003; RRID:AB_2338478), (CAR)Cy5 goat anti-rabbit (1:400; Jackson ImmunoResearch Laboratories, catalog \#111-175-144; RRID: AB_2338013), (CtBP2)TRITC donkey anti-mouse (1:400; Jackson ImmunoResearch Laboratories, catalog \#715-025-151; RRID:AB_2340767), (PKCa,Calb) AlexaFluor 488 donkey anti-mouse (1:1000; Invitrogen, cata$\log$ \#A-21202; RRID:AB_141607), and AMCA-avidin (1:500; Vector Laboratories, catalog \#A-2008; RRID:AB_2336102).

Quantification and statistical analysis. For the TCS functions involving both WT and G2 mice, two-way ANOVA was used with the nominal factors being genotype and frequency. Holm-Sidak's procedure for pairwise multiple comparisons was performed to test the hypothesis that mean measurements obtained from G2 mice were not different from WT mice. A similar analysis using a three-way ANOVA was applied to comparisons of contrast sensitivity between G2 and G2::Cx36 mice with nominal factors being temporal frequency, genotype, and irradiance. High temporal frequencies where two or more mice exhibited TCS $=1$ were not included in the analysis to minimize the skewing of the variance by non-responding mice. Two-way repeated-measures (RM) ANOVAs were performed to compare pupil areas (and retinal irradiance values) of WT, G1, G2, and G2::Cx36 mice; nominal factors being pupil area (or retinal irradiance) and corneal irradiance. When necessary, logarithmic transformations of data were performed before statistical analysis to fulfill normality and equal variance requirements for the ANOVA. In the case of the contrast sensitivity versus retinal irradiance functions (behavior) or magnitude versus retinal irradiance (ERG data), two-way RM ANOVA was performed independently at each temporal frequency with the nominal factors being genotype and irradiance. Data to compare critical flicker frequency values of WT and G2 mice did not pass normality tests, thus, a one-way ANOVA on ranks was performed. For quantification of outer nuclear layer (ONL) and outer plexiform layer (OPL) thickness measurements at both 500 and $800 \mu \mathrm{m}$, a two-way RM ANOVA was performed. Data analysis was performed with SigmaStat software (Systat Software). All plots display mean \pm SEM. In some cases, error bars are smaller than symbols. Numbers of mice and $p$ values are indicated in the figure legends.

\section{Results \\ Validation of the black GNAT2 ${ }^{\mathrm{cpfl3}}$ mouse model to isolate rod-driven responses}

We sought to determine the properties of rod-driven TCS in mesopic lights, while minimizing cone contributions. Selective stimulation of rods in wild-type mice with standard stimuli such as chromatic adaptation or silent substitution methods is not feasible, because mouse rod absorption spectra overlap closely with those for M-cones (Jacobs et al., 1991; Nikonov et al., 2006; Wang et al., 2011; Allen and Lucas, 2016). To circumvent this problem, we studied TCS in mice that carry a spontaneous point mutation in the GNAT2 gene that reduces cone phototransduction efficacy, GNAT2 ${ }^{\text {cpfl3 }}$ (Chang et al., 2006; for routing schematic, see Fig. $1 B$ ). GNAT2 ${ }^{\text {cpfl3 }}$ mice display normal rod responses and desensitized cone responses that can only be detected with intense flashes (Chang et al., 2006; Allen et al., 2010; Brown et al., 2011). However, before using GNAT2 ${ }^{\text {cpfl3 }}$ mice for our behavioral studies we addressed two potential confounds in these mice: (1) a thinning of the outer nuclear layer by 4 months of age as reported in albino GNAT2 ${ }^{\mathrm{cpfl3}}$ mice (Chang et al., 2006), and (2) residual cone activity in GNAT2 ${ }^{\mathrm{cpfl} 3}$ mice that may mask rod responses under the mesopic illumination conditions used for our operant behavior studies.

To minimize retinal degeneration and thinning of the ONL that is intrinsic to albino backgrounds such as GNAT2 ${ }^{\mathrm{cpfl3}}$ mice (LaVail, 1980; Rapp and Williams, 1980; Naash et al., 1996), we bred the GNAT2 ${ }^{\text {cpfl3 }}$ line onto the C57BL/6J ("black") background. We refer to this crossed line as G2. No overt anatomical changes were observed in retinas of G2 mice at 3-6 months of age, the time period of our behavioral studies (Fig. 2A-D). Measurements of ONL and OPL thickness indicate no significant thinning of G2 retinas up to 6 months of age at distances of 500 and $800 \mu \mathrm{m}$ from the optic nerve [Fig. 2A; no significant difference in genotype $(p=0.558)$ or genotype $\times$ location interactions $(p=0.065)$, two-way RM ANOVA]. We observed no aberrant sprouting of Calbindin-expressing horizontal cell processes in G2 or $\mathrm{G} 2:: \mathrm{Cx} 36$ mice (Fig. $2 B-B^{\prime \prime}$ ), which are typically present in mice with synaptic deficiencies (Bayley and Morgans, 2007). The double-transgenic G2::Cx36 mice have both disrupted cone responses and disrupted Cx36-dependent rod circuits (Fig. 1C). Coimmunolabeling for rod bipolar cells ( $\mathrm{PKC} \alpha$; green), ribbon synapses (CtBP2; red), and cone terminals (PNA; blue) indicated only occasional ectopic bipolar cell synaptic processes that extend into the ONL, similar to those observed in WT retinas (Fig. 2C$C^{\prime \prime}$, arrows). The apposed expression of CtBP2 and PNA at the base of cone terminals in control, G2, and G2::Cx36 retinas is 


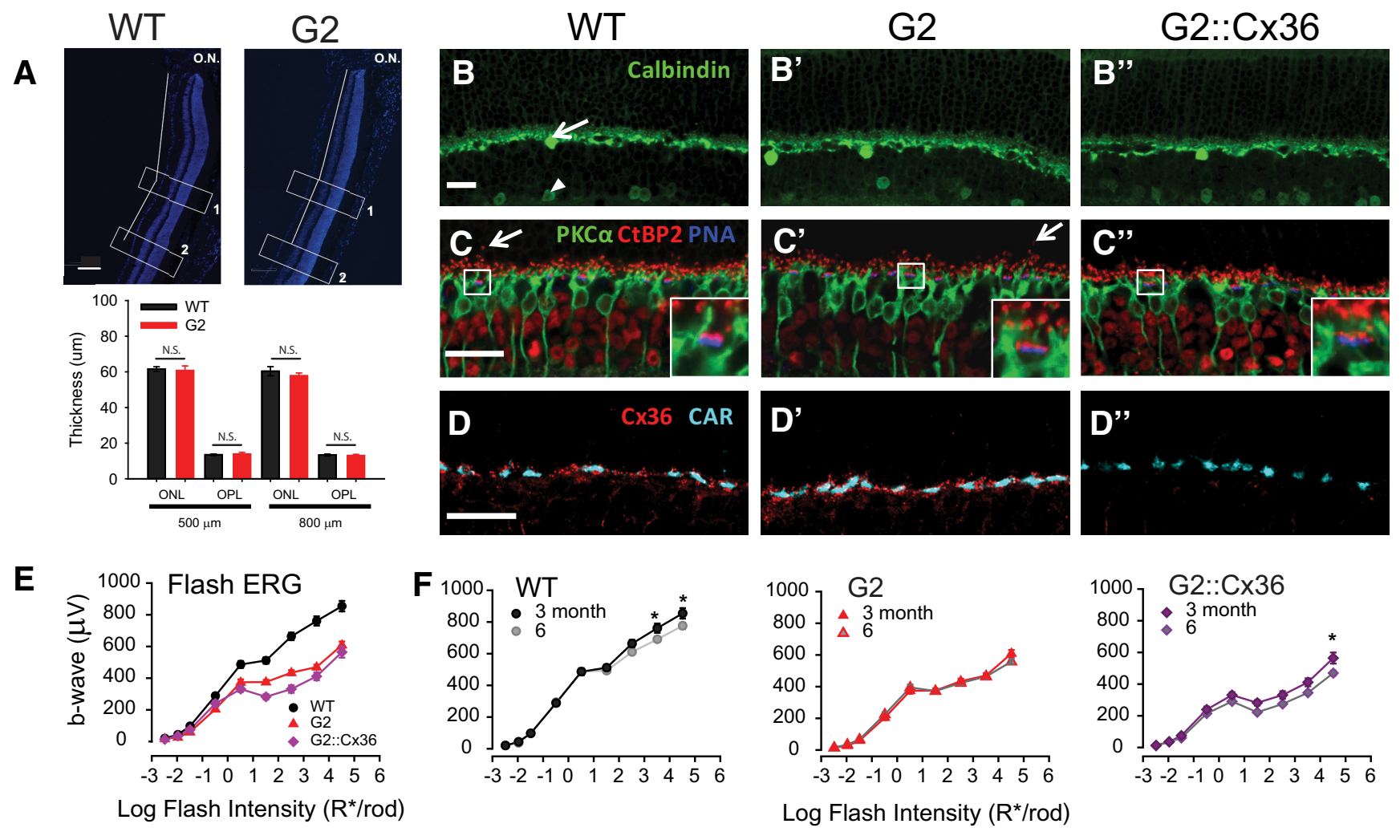

Figure 2. No overt degeneration or remodeling in G2 mouse retinas. $A$, Similar thickness in the ONL and OPL of 6 month WT and G2 retinas. Top, Representative vertical sections labeled with DAPI. Optic nerve head labeled ON. Thickness measurements were performed in two distinct regions: (1) 500 and (2) $800 \mu \mathrm{m}$ from optic nerve (white boxes). Bottom, ONL and OPL thickness is not significantly different (N.S.) at $500 \mu$ or $800 \mu \mathrm{m}$ (two-way RM ANOVA; see Results). $n=4$ mice, $3-4$ sections/mouse. Scale bar, $100 \mu \mathrm{m}$. $\boldsymbol{B}-\boldsymbol{D}$, Confocal images of immunolabeled retinal sections show normal retinal structures in 6 month WT $(\boldsymbol{B}-\boldsymbol{D}), \mathrm{G} 2\left(\boldsymbol{B}^{\prime}-\boldsymbol{D}^{\prime}\right)$ and G2:: $\mathrm{Cx36}$ retinas $\left(\boldsymbol{B}^{\prime \prime}-\boldsymbol{D}^{\prime \prime}\right)$. $\boldsymbol{B}-\boldsymbol{B}^{\prime \prime}$, Calbindin (green) labels horizontal cells (arrow) and some types of amacrine cells (arrowhead). $\mathbf{C}-C^{\prime \prime}$, Immunolabeling of rod bipolar cells with antibody against PKC $\alpha$ (green), ribbon synapses in photoreceptor terminals with antibody against CtBP2 (red) and cone terminals labeled with PNA (blue). Arrows point to representative extended rod bipolar cell dendrites rarely observed in both WT and G2 retinas. Insets show detailed synaptic structure of boxed regions. $\boldsymbol{D}-\boldsymbol{D}^{\prime \prime}$, Immunolabeling of $\mathrm{Cx36}$ gap junctions with antibody against Connexin 36 (Cx36, red) and cone terminals with antibody against cone arrestin (CAR, cyan). Scale bars, $20 \mu \mathrm{m}$. $E$, Amplitudes of dark-adapted flash ERG b-waves as a function of rod photoisomerizations elicited by brief flashes for WT (black circles; $n=10$ ), G2 (red triangles; $n=10$ ), and G2:: $:$ X36 mice (purple diamonds; $n=$ 10) at 3 months of age. G2 and G2::CX36 mice exhibit normal rod-driven flash ERG responses and reduced cone-driven flash ERG responses. Statistical analysis: two-way RM ANOVA; see text for details. Error bars: SEM is indicated but generally smaller than the size of the symbols. $\boldsymbol{F}$, b-wave amplitudes of WT, G2, and G2::Cx36 mice measured at 3 and 6 months of age. Minor changes in amplitude suggest no significant degeneration or remodeling during the time course of experiments. Statistical analysis: two-way RM ANOVA, ${ }^{*} p<0.05$; see text for details.

consistent with the presence of synaptic ribbons in cones (Fig. $2 C-C^{\prime \prime}$, insets). These findings support the notion that G2 mice exhibit no overt morphological signs of retinal degeneration or remodeling up to 6 months. Cx36 gap junctions between rod and cone photoreceptors provide the first step in the transmission of rod signals along the Cx36-dependent secondary rod pathway (Deans et al., 2002; Völgyi et al., 2004). Both WT and dysfunctional $\mathrm{G} 2$ cones express $\mathrm{Cx} 36$ gap junctions at the cone terminal (Fig. $2 D-D^{\prime}$ ), with no obvious morphological changes. As expected, Cx36 was not observed in G2::Cx36 retinas (Fig. $2 D^{\prime \prime}$ ).

Dark-adapted-flash ERGs of 3-month-old G2 and G2::Cx36 mice exhibited reduced b-wave amplitudes compared with WT mice (Fig. 2E; two-way RM ANOVA, significant genotype interactions: WT vs G2: $p=0.001$, WT vs G2::Cx36: $p=0.007$ ). Robust activation of rod pathways in the three genotypes was observed in response to scotopic flashes $\left(<-1 \log \mathrm{R}^{\star} /\right.$ rod). However, in response to higher flash intensities $\left(>-1 \log \mathrm{R}^{\star} / \mathrm{rod}\right)$ the intensity-response curves of G2 and G2::Cx36 mice peeled off gradually, as expected for reduced cone contributions. The responses of G2::Cx36 mice exhibited a further reduction in amplitude compared with G2 mice for flashes eliciting $>1 \log \mathrm{R}^{\star} / \mathrm{rod}$ [significant genotype $\times$ intensity interactions $(p<0.001)$, twoway RM ANOVA], consistent with a loss of function as described previously for $\mathrm{Cx} 36^{-1-}$ mice (Abd-El-Barr et al., 2009). Flash
ERG responses were relatively stable between 3 and 6 months only differing at the brightest flash intensity in WT and G2::Cx36 mice [Fig. 2F; significant time $\times$ stimulus interactions for WT $(p<0.001)$ and $\mathrm{G} 2:: \mathrm{Cx} 36$ mice $(p=0.014)$ but not for G2 mice $(p=0.060)]$, consistent with the notion that G2 and G2::Cx36 lines did not experience functionally significant remodeling or degeneration over the 3-6 month period of the behavioral studies.

We previously reported a sharp reduction in rod-driven optomotor sensitivity in albino GNAT2 ${ }^{c f f l}$ mice at illumination levels eliciting $>-4.5 \log \mathrm{cd} / \mathrm{m}^{2}(-1.6 \log \mathrm{R} * / \mathrm{rod} / \mathrm{s}$; Umino et al., 2008). In contrast, black G2 mice have robust optomotor responses that extend to at least $2 \log \mathrm{cd} / \mathrm{m}^{2}\left(3 \log \mathrm{R}^{\star} / \mathrm{rod} / \mathrm{s}\right.$; Fig. $3 A$ ). To determine whether this response arose from residual cone activity, we compared optomotor responses of black G2 mice with those of GNAT1 ${ }^{-1-}:: \mathrm{GNAT}^{2 \text { cpfl3 }}$ (G1::G2) doublemutant mice that lack rod function (Calvert et al., 2000) and have impaired cone phototransduction bred on a C57BL/6J congenic background (Fig. 1E). The G1::G2 mice have negligible optomotor sensitivity in response to $1500 \mathrm{R}^{\star} / \mathrm{rod} / \mathrm{s}$ (Fig. 3B), confirming that the responses in G2 mice arise largely from rods and not from desensitized cones. However, sensitivity of G1::G2 mice increased significantly at 50,000 $\mathrm{R}^{\star} / \mathrm{rod} / \mathrm{s}$ (Fig. $3 B$ ), consistent with residual cone responses at high irradiance levels. These results show that 

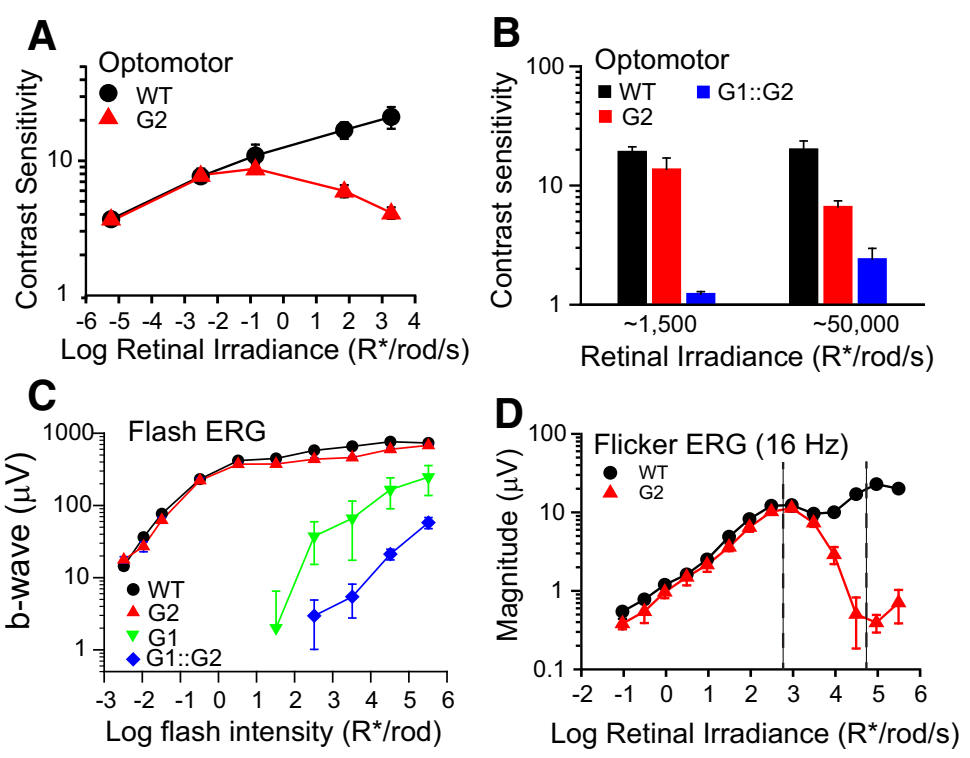

Figure 3. Desensitized cone responses of $\mathrm{G} 2$ mice do not mask rod responses at the mesopic light levels used in this study. $\boldsymbol{A}$, Optomotor contrast sensitivity of WT (black circles; $n=4$ ) and G2 mice (red triangles; $n=6$ ) plotted as a function of rod photoisomerizations. Grating parameters: $f_{\mathrm{t}}=3 \mathrm{~Hz}, f_{\mathrm{s}}=0.128 \mathrm{cyc} / \mathrm{deg}$. $\boldsymbol{B}$, Optomotor contrast sensitivity of WT (black bars; $n=$ 5), G2 (red bars; $n=5$ ) and G1::G2 mice (blue bars; $n=6$ ) measured at backgrounds levels of $1500 \mathrm{R}^{*} / \mathrm{rod} / \mathrm{s}$ and $50,000 \mathrm{R}^{*} / \mathrm{rod} / \mathrm{s}$. Grating parameters: $f_{\mathrm{t}}=1.5 \mathrm{~Hz}, f_{\mathrm{s}}=0.128 \mathrm{cyc} / \mathrm{deg}$. C, Amplitudes of dark-adapted flash ERG b-waves as a function of $R^{*} / \mathrm{rod}$ for WT (black circles; $n=5$ ), G2 (red triangles; $n=6$ ), G1 (green inverted triangles; $n=5$ ), and G1::G2 mice (blue diamonds; $n=6$ ). $D$, Magnitudes of the response at the fundamental frequency in the flicker ERG response of WT (black circles; $n=3$ ) and $G 2$ mice (red triangles; $n=3$ ) in response to a $16 \mathrm{~Hz}$ sinusoidal stimulus, $100 \%$ in contrast and indicated mean retinal irradiance. Region between dashed lines represents the intensity range over which subsequent operant behavior experiments were performed. All mice were $2-4$ months old.

(1) the reduced range of responses of albino G2 mice that we reported previously (Umino et al., 2008) were associated with the albino background and (2) rod-driven responses in black G2 mice are functional over an extended mesopic range. A possible explanation for the genotypic difference is that the higher rate of photoisomerizations reaching the photoreceptors across the transparent eye and pupil of the albino mice will drive the rods into saturation at lower ambient light levels compared with that observed in the pigmented C57BL/6J background (Lyubarsky et al., 2004; Nathan et al., 2006; Naarendorp et al., 2010). Such differences in pigmentation were not accounted for in the original study (Umino et al., 2008).

Dark-adapted flash ERGs of G1::G2 mice exhibit robust b-wave responses to flashes $>2 \log \mathrm{R}^{\star} / \operatorname{rod}$ (Fig. $3 C$ ), consistent with previous reports (Allen et al., 2010; Brown et al., 2011). Notably, the responses of G1::G2 mice are shifted to the right by $\sim 1.5 \log \mathrm{R}^{\star} /$ rod relative to the responses of G1 mice, suggesting a 30 -fold loss in sensitivity in cones of G2::G1 mice relative to those of G1 mice. To better assess the influence of the residual cone input in the light-adapted conditions of our behavioral studies, we compared ERG responses of WT and G2 mice to $16 \mathrm{~Hz}$ sinusoidal flicker presented at increasing irradiance levels (Fig. 3D). The magnitude of the flicker responses of WT mice followed a non-monotonic relation with two local maxima: a first peak at low irradiance levels $\left(2.5-3 \log \mathrm{R}^{\star} / \mathrm{rod} / \mathrm{s}\right)$ attributed to roddriven responses and a second peak at higher irradiance levels (5 $\log \mathrm{R}^{\star} / \mathrm{rod} / \mathrm{s}$ ) attributed to cone-driven responses (Nusinowitz et al., 2007). The flicker responses of G2 mice matched closely with the responses of WT mice at low irradiance levels $(-1$ to $3 \log$ $\left.\mathrm{R}^{\star} / \mathrm{rod} / \mathrm{s}\right)$. However, as irradiance was increased past the first peak, the responses of G2 mice diverged from control responses and declined steadily over the next $\sim 2 \log$ increase in irradiance, consistent with diminished cone contributions to the light-adapted flicker ERG. The asymptotic reduction in magnitude of the response can be explained in terms of response attenuation as rods saturate in steady lights (Nakatani et al., 1991; Fortenbach et al., 2015; Grimes et al., $2018 \mathrm{~b})$. The declining trend reverted at irradiance levels $>5 \log \mathrm{R}^{\star} / \mathrm{rod} / \mathrm{s}$ and is consistent with intrusion of the desensitized cone response at high irradiance levels. We note that the irradiance at which the desensitized cone response is apparent in G2 mice $\left(\sim 5 \log \mathrm{R}^{\star} / \mathrm{rod} / \mathrm{s}\right)$ is shifted $\sim 30$-fold to the right relative to the irradiance where the G2 response peels-off from the WT response $(\sim 3.5 \mathrm{log}$; Fig. $3 D)$. These data are consistent with the relative desensitization observed in the flash ERGs, and suggest that the irradiance range of our operant behavior studies (Fig. 3D, marked regions) is below the region where cone intrusion is apparent.

\section{Rods are sufficient to mediate TCS to high but not low temporal frequencies in bright mesopic light levels}

Here we investigated the limits of roddriven behavioral TCS across the mesopic range. We measured TCSFs of WT and G2 mice at multiple mean retinal irradiance values using an alternative forced choice operant behavior assay (see Materials and Methods). At low mesopic light levels producing $\sim 400 \mathrm{ph} / \mathrm{s} / \mu \mathrm{m}^{2}$, the TCSFs of WT and G2 mice had similar and overlapping bandpass shapes with peak sensitivity of 2.7 at 12 $\mathrm{Hz}$ [Fig. $4 A$; no significant genotype $(p=0.51)$ or genotype $\times$ frequency interactions ( $p=0.981$ ), two-way ANOVA]. At $<12$ $\mathrm{Hz}$, TCS declined gradually to a plateau of $\sim 1.5$. At $>12 \mathrm{~Hz}$, TCS decreased sharply, crossing the abscissa (contrast sensitivity $=1$ ) at $30 \pm 2.2 \mathrm{~Hz}$. At this limiting frequency, mice can no longer discriminate a flickering light from a steady light, and it is therefore considered a measure of the critical flicker fusion (CFF) frequency. The close overlap of the TCSFs in WT and G2 mice suggest that at the low mesopic light level of $400 \mathrm{ph} / \mathrm{s} / \mu \mathrm{m}^{2} \mathrm{rod}$ pathways are sufficient to determine TCS over the range of temporal frequencies tested.

At brighter light levels producing $\sim 8000 \mathrm{ph} / \mathrm{s} / \mu \mathrm{m}^{2}$ the TCSFs of WT mice had a peak value of 3.2 at $24 \mathrm{~Hz}$ (Fig. $4 B$ ), as described previously (Umino et al., 2019). At $<24 \mathrm{~Hz}$, TCS decreased gradually to a plateau of $\sim 1.8$. AT $>24 \mathrm{~Hz}$, TCS declined sharply to a CFF of $42 \pm 1.1 \mathrm{~Hz}$. Thus, when the background light level is increased from intermediate to upper mesopic intensities, TCSFs of WT mice exhibit an increase in both the peak sensitivity and dynamic range. The TCSFs of G2 mice also shifted to higher frequencies (peak at $21-24 \mathrm{~Hz}$ ). but exhibited a reduction in TCS to low frequencies relative to WT mice, with a negligible response to $4.5-6 \mathrm{~Hz}$ flicker [Fig. $4 B$; significant genotype $(p<0.001)$ and genotype $\times$ frequency interactions $(p=0.005)$, two-way ANOVA]. TCS recovered gradually for temporal frequencies $<4.5 \mathrm{~Hz}$, but remained significantly lower than that of WT mice. At $>21 \mathrm{~Hz}$ the TCS of G2 mice declined sharply from its peak of 2.4 to a CFF at $36 \mathrm{~Hz}$, which is slightly lower than that observed for WT ( $42 \mathrm{~Hz} ; p=0.043$, one-way ANOVA on ranks). Thus, at 
A

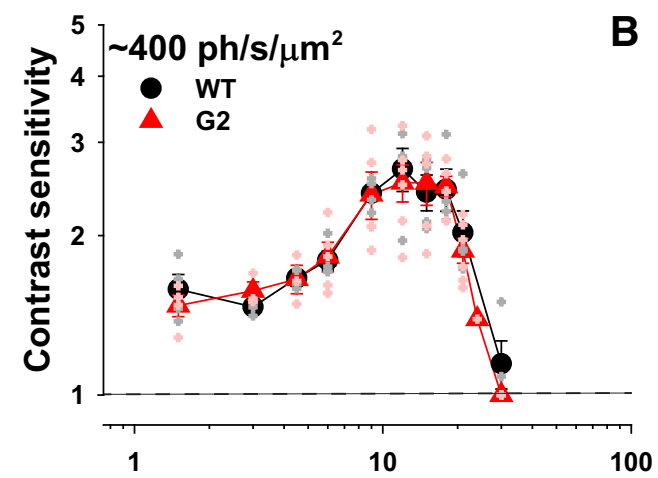

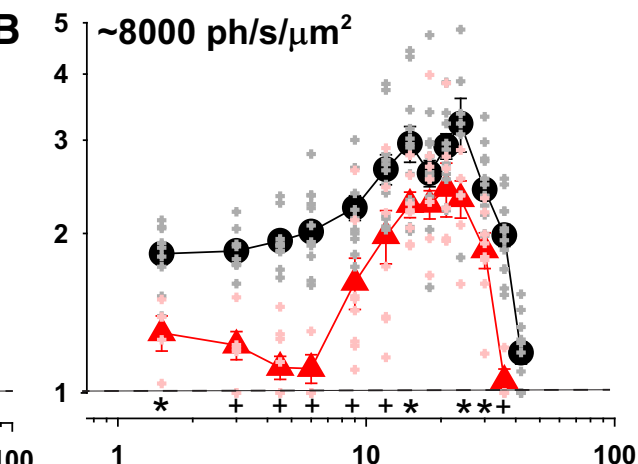

D 5

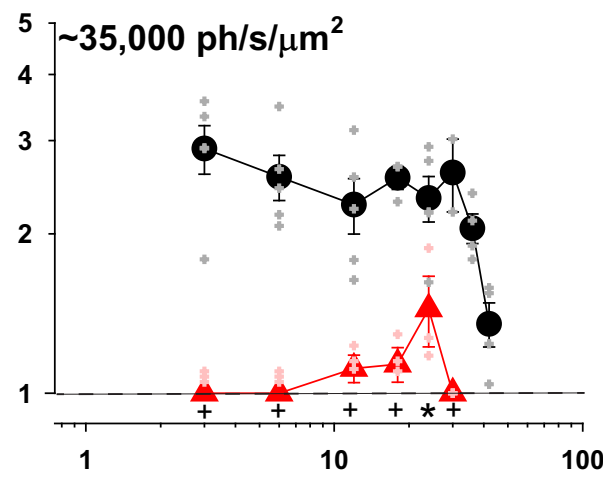

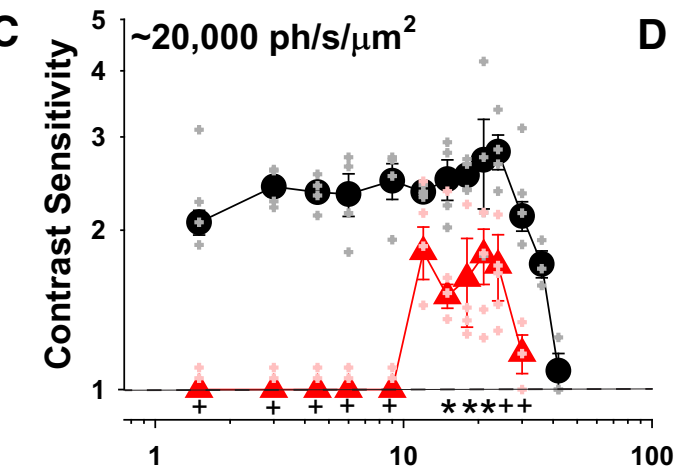

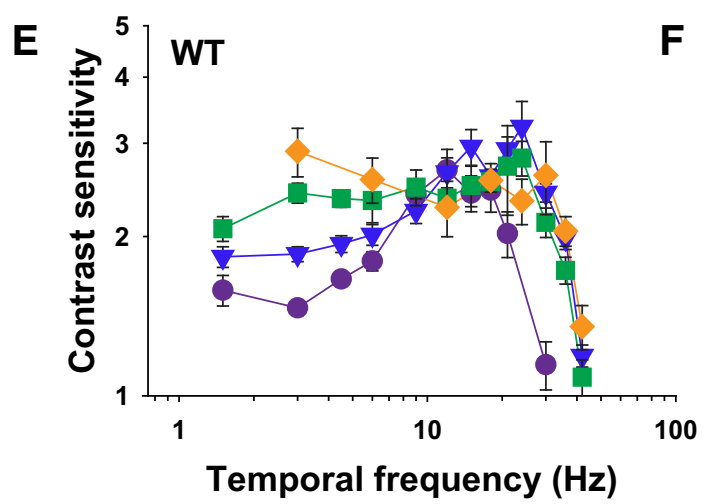

$\left.F^{5}\right] \mathbf{G}_{2}$

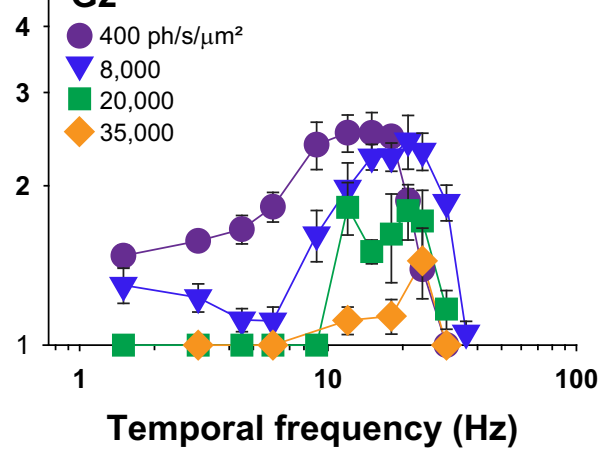

Figure 4. Rods are sufficient to mediate TCS to high but not low temporal frequencies in bright mesopic light levels. $\boldsymbol{A}-\boldsymbol{D}, \mathrm{T}, \mathrm{TSF}$ of WT (black circles) and $\mathrm{G} 2 \mathrm{mice}$ (red triangles) measured at mean retinal irradiance values of: (A) $400 \mathrm{ph} / \mathrm{s} / \mu \mathrm{m}^{2}$, WT $(n=4)$, and G2 mice $(n=3-6) ;(B) 8000 \mathrm{ph} / \mathrm{s} / \mu \mathrm{m}^{2}$, WT $(n=4-9)$, and G2 mice $(n=4-8) ;(C) 20,000 \mathrm{ph} / \mathrm{s} / \mu \mathrm{m}^{2}$, WT $(n=4)$, and G2 mice $(n=4-5)$; and (D) 35,000 ph/s/ $\mu \mathrm{m}^{2}$, WT ( $\left.n=3-5\right)$, and G2 mice $(n=3)$. Mice were 3-6 months old. Closed symbols represent mean \pm SEM, whereas the smaller, lighter symbols are responses of individual mice (WT, gray; G2, light red). Statistical analysis: two-way ANOVA (see text for details), frequency $\times$ genotype interactions: ${ }^{*} p<0.05$ and $+p<0.01$, all other interactions $p>0.05$. $\boldsymbol{E}, \boldsymbol{F}$, TCSFs over increasing background intensities for $(\boldsymbol{E})$ WT and $(\boldsymbol{F}) \mathrm{G} 2$ mice. Retinal irradiance values of WT and G2 mice were estimated using the pupil area values of freely behaving mice as described in Materials and Methods.

upper mesopic intensities, rods are sufficient to mediate high temporal frequencies in G2 mice with desensitized cones.

At higher retinal irradiances of $\sim 20,000-35,000 \mathrm{ph} / \mathrm{s} / \mu \mathrm{m}^{2}$ (top of the mesopic range) the TCSFs of WT mice acquired a low-pass shape without significant changes in the dynamic range (Fig. $4 C, D$ ). In contrast, at $\sim 20,000 \mathrm{ph} / \mathrm{s} / \mu \mathrm{m}^{2}$, G2 mice exhibited a loss in sensitivity to low temporal frequencies, resulting in a sharply tuned bandpass TCSF that spans from 12 to $30 \mathrm{~Hz}$ (Fig. $4 C$ ). Within this range, TCS was significantly reduced compared with WT (Fig. 4C; significant genotype interaction; $p<0.001$, two-way ANOVA). G2 mice showed only minimal TCS to $24 \mathrm{~Hz}$ at irradiance levels of $\sim 35,000 \mathrm{ph} / \mathrm{s} / \mu^{2}{ }^{2}$ [Fig. $4 D$; significant genotype $(p<0.001)$ and genotype $\times$ frequency interactions $(p=0.001)$, two-way ANOVA].

Plots of the families of TCSFs encapsulate the complex irradiance- and frequency-dependent transformations in the response properties of WT (Fig. 4E) and G2 (Fig. 4F) mice. With increasing background intensity, TCSFs of WT mice transformed progressively from a bandpass to a low pass shape, largely due to an increase in TCS to temporal frequencies $<9 \mathrm{~Hz}$ (Fig. 4E). At $>9 \mathrm{~Hz}$, WT TCSFs overlap closely and share a common asymptotic decrease in TCS to a CFF of $42 \mathrm{~Hz}$ (except for the TCSF at $400 \mathrm{ph} / \mathrm{s} / \mu \mathrm{m}^{2}$, which decreases sharply to a CFF of $24 \mathrm{~Hz}$ ). Light adaptation had the opposite effects on G2 mice (Fig. $4 F$ ). With increasing background intensity, TCS to low frequencies decreased, resulting in increasingly narrower TCSFs. Sensitivity to high temporal frequencies began to decrease at irradiance levels $>8000 \mathrm{ph} / \mathrm{s} / \mu \mathrm{m}^{2}$ and was almost negligible at $35,000 \mathrm{ph} /$ $\mathrm{s} / \mu \mathrm{m}^{2}$ levels. These results suggest that the loss in TCS in G2 mice originates from saturation of the rod responses in bright lights, and argue against the possibility that TCS is mediated by the intrusion of desensitized cone responses in G2 mice (Chang et al., 2006) or the intrinsic photoresponses of ipRGCs (Berson et al., 2002; Hattar et al., 2002; Schroeder et al., 2018). 


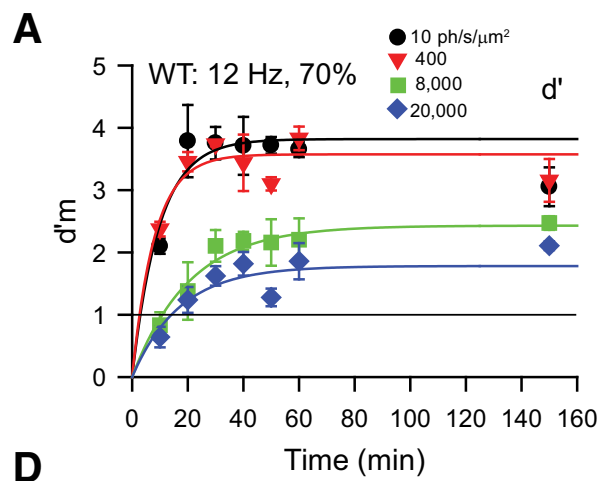

\section{Condition I (closed symbols)

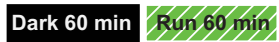

Condition II (open symbols)

Dark 60 min Light $60 \mathrm{~min}$ Run $60 \mathrm{~min}$

Both conditions: $21 \mathrm{~Hz}, 20,000 \mathrm{ph} / \mathrm{s} / \mu \mathrm{m}^{2}$

\section{G}

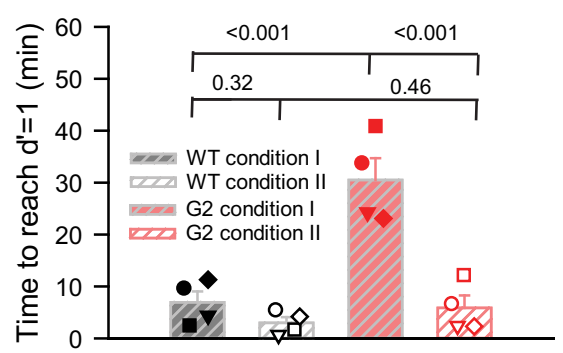

B

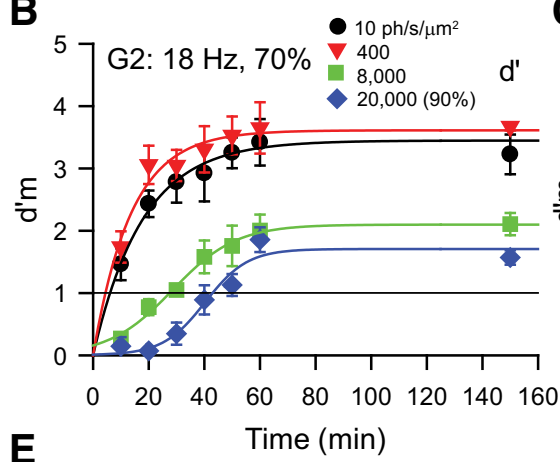

E

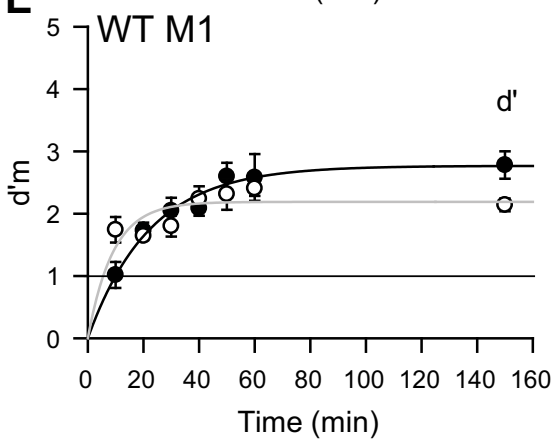

$\mathbf{F}$

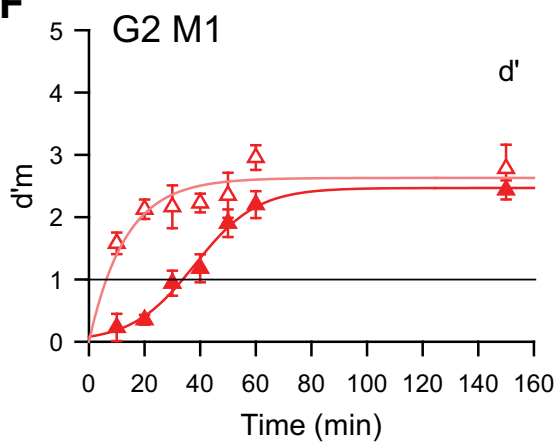

C

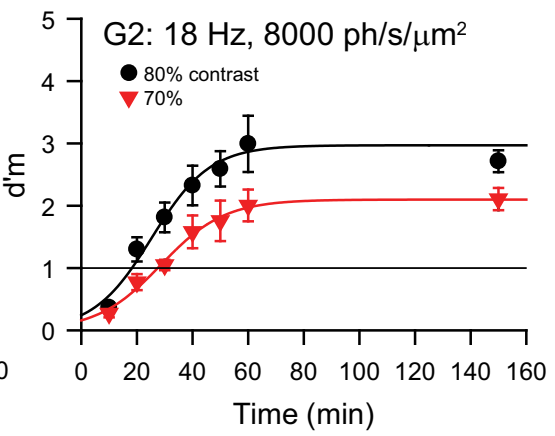

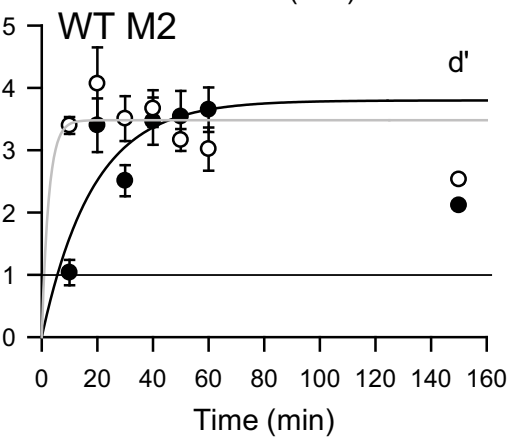

d'

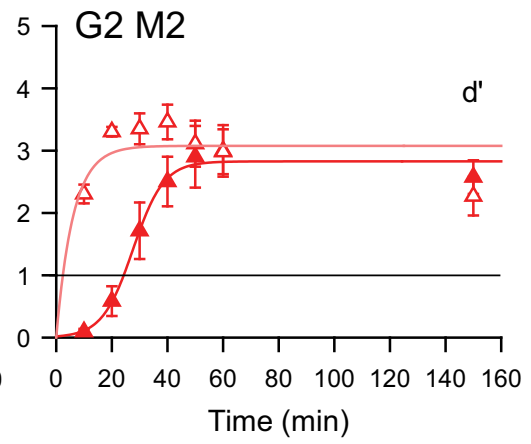

Figure 5. Rod-driven TCS to high temporal frequencies develops gradually over time. $A, B$, Values of $d^{\prime} m$ measured during corrective trials plotted as a function of time after the start of the trial. WT $(\boldsymbol{A})$ and G2 $(\boldsymbol{B})$ mice were dark-adapted for $1 \mathrm{~h}$ before the trial. Measurements were performed at indicated mean retinal irradiance levels. Flicker contrast was $70 \%$ in all cases except for the tests at $20,000 \mathrm{ph} / \mathrm{s} / \mu \mathrm{m}^{2}$, which were performed with $90 \%$ contrast flicker. Continuous lines represent fits with rising exponential functions (all curves in $A$; and response at 10 and $400 \mathrm{ph} / \mathrm{s} / \mu \mathrm{m}^{2}$ in $B$ ) and s-shaped hyperbolic functions $\left(\boldsymbol{B} ; 8000\right.$ and $\left.20,000 \mathrm{ph} / \mathrm{s} / \mu \mathrm{m}^{2}\right)$. Following the initial 60 min of each trial during which the corrective protocol (measured $d^{\prime} \mathrm{m}$ ) was run, we switched to the normal protocol (without corrective trials) and determined the average $d^{\prime}$ value over the subsequent $90 \mathrm{~min}$. The corresponding value of $d^{\prime}$ is indicated at time $t=150 \mathrm{~min}$. Symbols in these plots and in $\boldsymbol{C}, \boldsymbol{E}$, and $\boldsymbol{F}$ represent mean $\pm \mathrm{SEM} ; n=4-6$ runs in each condition. $\boldsymbol{C}$, The time course of $d^{\prime} m$ plotted as a function of time for a $\mathrm{G} 2 \mathrm{mouse}$ tested at $8000 \mathrm{ph} / \mathrm{s} / \mu \mathrm{m}^{2}$ and flicker contrasts 80 and $70 \%$. Flicker frequency was $18 \mathrm{~Hz}$. D, Experimental design applied to studies described in $\boldsymbol{E}$ and $\boldsymbol{F}$. In Condition 1, mice are tested immediately after a 60 min dark-adaptation period $(\boldsymbol{E}, \boldsymbol{F}$, closed symbols); in Condition 2, mice undergo a $60 \mathrm{~min}$ light adaptation period before testing ( $\boldsymbol{E}, \boldsymbol{F}$, open symbols). Retinal irradiance during the light adaptation period was $20,000 \mathrm{ph} / \mathrm{s} / \mu \mathrm{m}^{2}$. Flicker frequency was $21 \mathrm{~Hz}$, and the contrast was adjusted individually to elicit a $d^{\prime}$ value ranging from 2 to 2.5 . $E$, $F$, Values of $d^{\prime} m$ plotted as a function of time measured with Condition I (closed symbols) and Condition 2 (open symbols). $\boldsymbol{E}, d^{\prime} m$ values for two representative WT mice (WT M1, WT M2) do not vary with experimental condition; $(\boldsymbol{F}) d^{\prime} m$ values for G2 mice (G2 M1, G2 M2) rise later in Condition 1 compared with Condition 2. TTR was determined at the intersection of the fitting functions with the line representing $d^{\prime} m=1$ (see $\boldsymbol{G}$ ). Fitting functions were rising exponential for all data of $(\boldsymbol{E})$ and data determined under condition 2 in $(\boldsymbol{F})$. Hyperbolic functions fit the responses to condition 1 in $(\boldsymbol{F})$. $\boldsymbol{G}$, TTR for four WT and four $\mathrm{G} 2$ mice measured under Conditions 1 and 2 . Analysis: two-way RM ANOVA, Holm-Sidak method; corresponding $p$ values for pairwise comparisons are indicated on graph. See text for details.

These two alternative possibilities would predict constancy or strengthening of the responses as light levels increase within this range.

\section{Rod-driven TCS to high temporal frequencies develops gradually over time}

During our testing, we observed that G2 (but not WT) mice were relatively insensitive to flicker during the first $10-15 \mathrm{~min}$ of the corrective trials intended to familiarize mice with high irradiance and high-frequency properties of the test stimulus (for details of the corrective trials, see Materials and Methods; Umino et al., 2018 ). To quantitatively characterize these behavioral differences between the two genotypes, we systematically tested their sensitiv- ity to high frequencies eliciting maximal sensitivity (e.g., 12-21 Hz). At dim irradiance levels producing 10 and $400 \mathrm{ph} / \mathrm{s} / \mu \mathrm{m}^{2}$ at the retina, the $d^{\prime} m$ values ( $d^{\prime}$ measured during corrective trials; Umino et al., 2018) of both WT (Fig. 5A) and G2 (Fig. 5B) mice rose quickly to its asymptotic value with a time course that is well fit by rising exponential functions $\left(R^{2}>0.7\right)$. At higher irradiance levels producing 8000 and $20,000 \mathrm{ph} / \mathrm{s} / \mu \mathrm{m}^{2}, d^{\prime} m$ values of WT mice also grew rapidly along an exponential function $\left(R^{2}>0.7\right)$; however, those of $\mathrm{G} 2$ mice followed an s-shaped hyperbolic time course that grew at a slower rate than that of WT mice $\left(R^{2}>0.9\right)$. To compare the responses of WT and G2 mice we define the time to response (TTR) as the time that a behaving mouse requires to reach the threshold value of $d^{\prime} m=$ 1. TTR increased with irradiance (Fig. $5 A, B$ ) but decreased with 

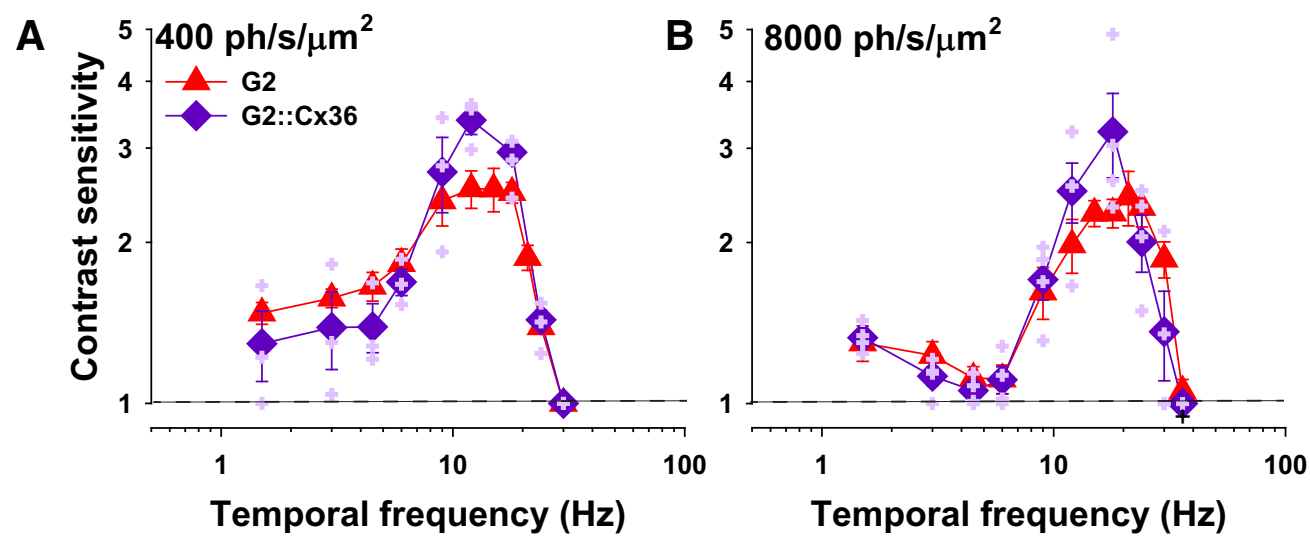

Figure 6. Cx36-independent rod pathways are sufficient to relay rod-driven TCS to high temporal frequencies. $A, B$, TCSFs of G2 (red triangles) and G2:: $(x 36$ mice (purple diamonds) measured at mean retinal irradiance values of $(\boldsymbol{A}) 400 \mathrm{ph} / \mathrm{s} / \mu \mathrm{m}^{2}, \mathrm{G} 2(n=3-6)$ and G2::CX36 mice $(n=3) ;(\boldsymbol{B}) 8000 \mathrm{ph} / \mathrm{s} / \mu \mathrm{m}^{2}, \mathrm{G} 2(n=4-9)$ and G2::CX36 mice $(n=4)$. Mice were 3-6 months old. Closed symbols represent mean $\pm \mathrm{SEM}$, whereas the smaller, lighter purple symbols are responses of individual G2::Cx36 mice. Data for individual $\mathrm{G} 2$ mice are shown in Figure 4. Statistical analysis: two-way or three-way ANOVA; see text for details. Retinal irradiance values of G2 and G2::: $\times 36$ mice were estimated using the pupil area values of freely behaving mice as described in Materials and Methods.

flicker contrast as shown for a representative G2 mouse (Fig. 5C). Similar results were observed in two WT and two G2 mice.

We quantitatively assessed the kinetics of the time-dependent rise of $d^{\prime} m$ by systematically comparing the TTR to $21 \mathrm{~Hz}$ in four WT and G2 mice. A flicker frequency of $21 \mathrm{~Hz}$ was chosen, because it is the value that elicits the maximal response in $\mathrm{G} 2$ mice (Fig. $4 C, D$ ). All mice were exposed to $20,000 \mathrm{ph} / \mathrm{s} / \mu \mathrm{m}^{2}$, and flicker contrast was adjusted individually to elicit similar $d^{\prime}$ values (ranging from 2.5 to 3 ) in each mouse. TTR values were determined by interpolation of the rising exponential and s-shaped functions fitting the WT and G2 responses, respectively. Under experimental condition 1 (Fig. 5D), mice were run immediately after the $1 \mathrm{~h}$ dark-adaptation period. In this condition, the sensitivity of WT mice developed quickly, resulting in a TTR value of 10 min or less (Fig. 5E, closed symbols), whereas G2 mice had a TTR value of $\sim 30 \mathrm{~min}$ (Fig. $5 F$ ). To determine whether prior exposure to light (light-adaptation) alters the TTR, we tested mice with Condition 2 (Fig. $5 E, F$, open symbols) where mice were exposed to steady light for $60 \mathrm{~min}$ before the test (Fig. 5D). In these conditions TTR in WT mice did not change significantly, remaining $<10$ min, whereas TTR in G2 mice decreased to levels observed in WT mice [Fig. 5G; significant genotype $\times$ condition interaction ( $p=0.002)$, two-way ANOVA; $p$ values for pairwise comparisons (Holm-Sidak method) indicated in plot]. Note that the asymptotic value of $d^{\prime} m$ measured at the end of the runs (60 min) can match (e.g., WT M1 and G2 M1) or overestimate (e.g., WT M2 and G2 M2) the discriminability factor $d^{\prime}$ determined following a $1.5 \mathrm{~h}$ trial without corrective intervention (indicated at time $=150 \mathrm{~min}$ ), suggesting that corrective trials can improve decision-making in some mice. Our results suggest that the contributions of rods to TCS depend not only on the irradiance and frequency of the flicker, but also on the time of light adaptation (Tikidji-Hamburyan et al., 2017).

Cx36-independent rod pathways are sufficient to relay roddriven TCS to high temporal frequencies

To dissect the contributions of Cx36-dependent and Cx36independent rod pathways to TCS we compared TCSFs of G2 and G2::Cx36 double-mutant mice. Figure 1 illustrates the targets of disruption in G2 and G2::Cx36 mice. G2 mice have disrupted cone responses while their rod pathways remain largely intact (Fig. 1B). In contrast, G2::Cx36 mice have both disrupted cone responses and disrupted Cx36-dependent rod circuits (which includes the canonical secondary pathway and $\mathrm{ON}$ branch of the primary rod pathway) leaving only functional Cx36-independent rod pathways (tertiary pathway and OFF branch of the primary rod pathway which drive primarily OFF and not ON retinal ganglion cells; Fig. 1C).

At $400 \mathrm{ph} / \mathrm{s} / \mu \mathrm{m}^{2}$, TCSFs of G2 and G2::Cx36 mice have a similar characteristic bandpass shape [Fig. $6 A$; no significant genotype $(p=0.549)$ or genotype $\times$ frequency interactions $(p=$ 0.108 , power $=0.3)$, two-way ANOVA]. At the brighter, mesopic, light level of $8000 \mathrm{ph} / \mathrm{s} / \mu \mathrm{m}^{2}$, TCSFs of G2 and G2::Cx36 mice again have similar TCSFs [Fig. $6 B$; no significant genotype $(p=0.746)$ or genotype $\times$ frequency interactions $(p=0.139$, power $=0.35$, two-way ANOVA]. The small difference in TCS at $12-18 \mathrm{~Hz}$ was not statistically different. However, a linear model with three nominal variables (temporal frequency, genotype, and irradiance levels) improves the power of the statistical test and demonstrates higher TCS in G2::Cx36 than in G2 mice at 12 and $18 \mathrm{~Hz}$, but not at lower frequencies [genotype $\times$ frequency interactions $(p=0.009$, power $=0.83)$, three-way ANOVA, multiple comparisons with Holm-Sidak method, $p<0.001$ for genotype within $12 \mathrm{~Hz}, p=0.033$ for genotype within $18 \mathrm{~Hz}$, and $p>0.05$ for all other frequencies]. Together, these results suggest that, despite a minor difference in TCS at 12-18 Hz, (1) Cx36dependent rod pathways are not required for TCS at the mesopic light levels tested; and (2) Cx36-independent rod pathways can relay both low and high temporal frequencies at lower mesopic light levels (400 $\mathrm{ph} / \mathrm{s} / \mu^{2} \mathrm{~m}^{2}$ ), but largely high frequencies at upper mesopic lights $\left(8000 \mathrm{ph} / \mathrm{s} / \mu \mathrm{m}^{2}\right)$. Furthermore, WT, G2 and G2:: Cx36 mice have similar TCS at $400 \mathrm{ph} / \mu \mathrm{m}^{2} / \mathrm{s}$ (compare the TCS functions in Figs. 4A, 6A). Given that Cx36-independent pathways are thought to drive largely OFF and not ON ganglion cells (Fig. 1C), these results raise the interesting possibility that $\mathrm{ON}$ pathways are not major contributors to perceptual flicker detection in either G2 or WT mice under these experimental conditions. Future experiments are required to determine whether these results arise from a shift in the dynamic balance between $\mathrm{ON}$ and $\mathrm{OFF}$ pathways under our experimental conditions.

\section{The mesopic range shifts with temporal frequency}

Rods and cones are canonically accepted to relay slow and fast signals, respectively. However, comparison of TCS in WT and G2 


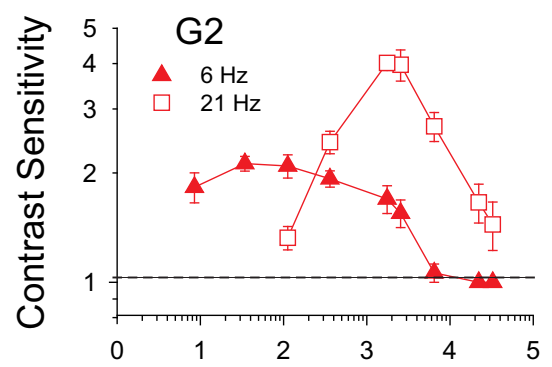

Log Retinal Irradiance $\left(\mathrm{ph} / \mathrm{s} / \mu \mathrm{m}^{2}\right)$

C

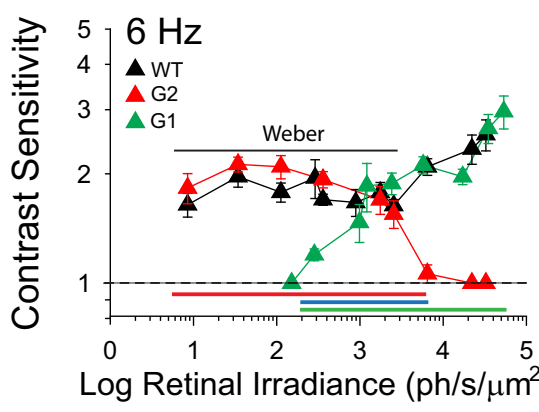

B

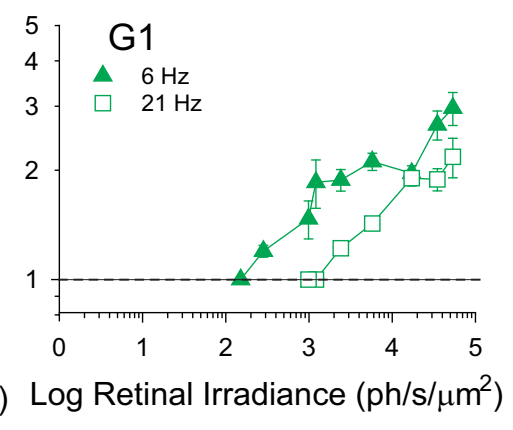

D

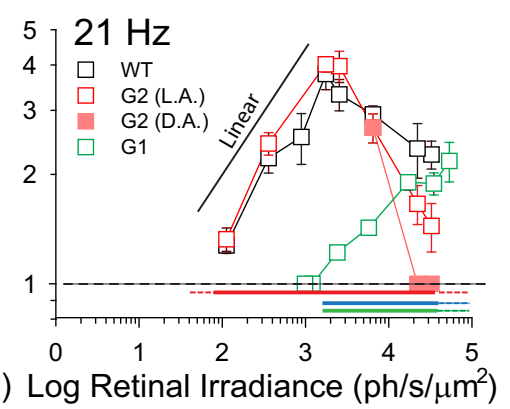

Figure 7. The mesopic range shifts with temporal frequency. $A, B$, Contrast sensitivity as a function of retinal irradiance for $(A)$ G2 mice at $6 \mathrm{~Hz}$ (filled red triangles; $n=4-9$ ) and $21 \mathrm{~Hz}$ (open red squares; $n=3-8$ ); and (B) $\mathrm{G} 1$ mice at $6 \mathrm{~Hz}$ (filled green triangles; $n=4-5$ ) and $21 \mathrm{~Hz}$ (open green squares; $n=3-4)$. C, $\boldsymbol{D}$, Contrast sensitivity as a function of retinal irradiance for WT (black; $n=4-11$ ), G2 (red; $n=3-9$ ), and G1 (green; $n=4-5$ ) mice at: (C) $6 \mathrm{~Hz}$ and (D) $21 \mathrm{~Hz}$. Sensitivity values in $\boldsymbol{A}-\boldsymbol{D}$ are plotted as a function of the WT retinal irradiance (for WT and G2 mice) or corrected for phenotypic differences in pupil areas (for G1 mice). See Table 1 for respective pupil area and retinal irradiance values. Note: for light conditions where pupil areas were not measured, $\mathrm{G} 1$ retinal irradiance values were determined by interpolation of data. Filled pink squares in (D) represent dark-adapted (DA) G2 data and open red squares represent light-adapted (LA) G2 data as described in Figure 5. Red bars represent the intensity range over which rods are active in $\mathrm{G} 2$ mice, green bars represent the intensity range over which cones are active in $\mathrm{G} 2$ mice, and blue bars represent the mesopic range over which both rods and cones are active. Dashed red, green, and blue lines in (D) represent extrapolated values. Statistics: two-way ANOVA, $p$ values for pairwise comparisons are shown in the figure.

Comparison of TCS in WT, G2, and G1 mice helps delimit the regions where rods and cones may contribute to TCS in WT mice. At $6 \mathrm{~Hz}$, WT and G2 mice have similar TCS at irradiance values of $10-$ $3000 \mathrm{ph} / \mathrm{s} / \mu \mathrm{m}^{2}$, but sensitivity of G2 mice are significantly reduced at higher intensities [Fig. 7C; significant genotype ( $p<$ $0.001)$ and genotype $\times$ intensity interactions $(p<0.001)$, two-way ANOVA]. This suggests that rods are sufficient to drive low $(6 \mathrm{~Hz})$ temporal frequency TCS at retinal irradiance levels of up to 3000 $\mathrm{ph} / \mathrm{s} / \mu \mathrm{m}^{2}$. Analogously, WT and G1 mice have similar TCS at irradiance values $>1000 \mathrm{ph} / \mathrm{s} / \mu \mathrm{m}^{2}$, consistent with the notion that cones drive TCS at higher irradiance values (Fig. $7 C$; note that retinal irradiance values of the measurements do not always match because of differences in respective pupil areas in WT and G1 mice; see Materials and Methods; Table 1; and as a consequence we were not able to statistically compare TCS in WT and G1 mice). WT, G1, and G2 mice have similar TCS values for irradiance values between 1000 and $3000 \mathrm{ph} / \mathrm{s} / \mu \mathrm{m}^{2}$ (Fig. 7C; twoway ANOVA). These results suggest a potential interdependence between rod and cone pathways of WT mice (Walraven et al., 1990; Buck, 2014).

At $21 \mathrm{~Hz}, \mathrm{WT}$ and G2 mice have similar TCS at irradiance values of $100-8000$ $\mathrm{ph} / \mathrm{s} / \mu \mathrm{m}^{2}$ (Fig. $7 D$; significant genotype $\times$ intensity interactions, $p=0.05$, two-way ANOVA). This suggests that rods can drive TCS at much higher irradi-

mice at $8000 \mathrm{ph} / \mathrm{s} / \mu \mathrm{m}^{2}$ (Fig. $4 B$ ) suggest that at upper mesopic light levels, cones mediate TCS to low temporal frequencies $(6 \mathrm{~Hz})$, whereas rods, via Cx36-independent pathways, can mediate TCS to high temporal frequencies $(21 \mathrm{~Hz})$. To gain insights into the mechanisms underlying this paradoxical result we compared TCS in WT, G2 (low cone sensitivity) and G1 (no functional rods) mice (Fig. 1). Systematic measurements were focused on the responses to low $(6 \mathrm{~Hz})$ and high $(21 \mathrm{~Hz})$ flicker frequencies and performed in small irradiance increments $(0.3-0.6 \log$ increments) to resolve potential rod-rod or rod-cone interactions (MacLeod, 1972).

TCS of G2 mice to $6 \mathrm{~Hz}$ flicker remained relatively constant over an extended irradiance range $\left(10-3000 \mathrm{ph} / \mathrm{s} / \mu \mathrm{m}^{2}\right)$, consistent with Weber's law of adaptation (Umino et al., 2018, 2019), and declined sharply to negligible levels with higher irradiance levels (Fig. 7A, filled triangles). In contrast, TCS of G2 mice to 21 $\mathrm{Hz}$ exhibited a non-monotonic relation with a maximal value of 4 at $2000-3000 \mathrm{ph} / \mathrm{s} / \mu \mathrm{m}^{2}$ (Fig. $7 A$, open squares). TCS of G1 mice to $6 \mathrm{~Hz}$ flicker exhibited three distinct phases in the response: TCS first increased steadily for irradiance values between $100-1000 \mathrm{ph} / \mathrm{s} / \mu \mathrm{m}^{2}$, plateaued over the next $\sim 1.0 \log \mathrm{ph} / \mathrm{s} / \mu \mathrm{m}^{2}$ increase in irradiance and then resumed the increasing trend for irradiance values $>10,000 \mathrm{ph} / \mathrm{s} / \mu^{2}$ (Fig. $7 B$, filled triangles). TCS of G1 mice to $21 \mathrm{~Hz}$ followed the same trend as that observed in response to $6 \mathrm{~Hz}$, but is right-shifted by $\sim 1 \log$, which is consistent with a tenfold lower sensitivity (Fig. $7 B$, open squares). ance values when stimulated with higher $(21 \mathrm{~Hz})$ temporal frequencies compared with lower $(6 \mathrm{~Hz})$ temporal frequencies (Fig. 7, compare $C, D$ ). Prolonged light adaptation (Fig. 5) increased sensitivity of G2 mice at irradiance levels $>10^{4} \mathrm{ph} / \mathrm{s} / \mu \mathrm{m} 2$ (Fig. $7 D$, open red vs filled pink squares). Intriguingly, TCS of G1 mice is reduced compared with that of WT mice at irradiance levels $<20,000 \mathrm{ph} / \mathrm{s} / \mu^{2}{ }^{2}$ (Fig. $7 D$ ). These results suggest that cones may contribute to, but do not significantly drive the responses in WT mice within this range. They further indicate an essential role for rod pathways in mediating TCS at high mesopic irradiance levels and high temporal frequencies.

We loosely defined the mesopic range by the irradiance levels where significant TCS values are first detected in G1 (left or low range limit) mice and where G2 mice stop responding (right or high limit; Fig. $7 C, D$, blue lines) and mapped these values on a plot of flicker frequency versus irradiance (Fig. 8). In this plot, the area to the left of the G1 threshold line includes all irradiancetemporal frequency combinations where rods alone drive TCS. The area to the right of the G2 saturation line indicates conedriven TCS, whereas the overlapping region corresponds to the mesopic region (where TCS is expected to be driven by rods and/or cones). The upper frequency limit indicates the CFF values as measured for WT mice in Figure 4. Interestingly, the mesopic range shifts diagonally to the right as temporal frequency increases. As a result of this shift, the relative contribution of rods and cones to TCS at a given irradiance level changes with 


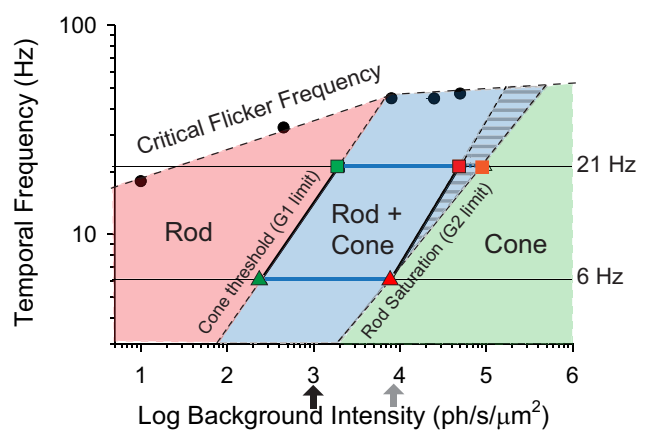

Figure 8. Map of rod and cone contributions to TCS. Irradiance versus Temporal Frequency adaptation map showing the irradiance-frequency combinations where contrast thresholds are driven largely by rods (pink), cones (green) and rod + cones (blue shading), loosely defining the conditions for scotopic, photopic, and mesopic temporal contrast vision in mouse, respectively. The transition between the pink and blue regions was inferred from the cone threshold values of $\mathrm{G} 1$ mice at $6 \mathrm{~Hz}$ (green triangle) and $21 \mathrm{~Hz}$ (green square), whereas the transition between blue and green regions was defined as the upper irradiance levels eliciting a behavioral response in $\mathrm{G} 2$ mice to $6 \mathrm{~Hz}$ (red triangle) and $21 \mathrm{~Hz}$ (red square) flicker respectively (Fig. 7). The blue region with stripes represents extrapolated sensitivity at high temporal frequencies (Fig. 6). The high-frequency boundary of the map (black circles) is determined by the (FF values for WT mice measured in this study (Fig. 4) and previously by Umino et al. (2018) (see CFF at 10 $\left.\mathrm{ph} / \mathrm{s} / \mu \mathrm{m}^{2}\right)$.

frequency: at low irradiance values $\left(1000 \mathrm{ph} / \mathrm{s} / \mu \mathrm{m}^{2}\right.$; Fig. 8 , black arrow), TCS to low frequencies $(6 \mathrm{~Hz})$ is driven by both rods and cones while the response to high frequencies $(21 \mathrm{~Hz})$ is driven largely by rods. Similarly, at $8000 \mathrm{ph} / \mathrm{s} / \mu \mathrm{m}^{2}$ (Fig. 8, gray arrow), TCS to low frequencies is driven largely by cones as the rod system saturates, while TCS to high frequencies is driven by both rods and cones.

\section{Relative contributions of M- and S-opsin-containing cones to TCS}

The retina of mice is sparsely populated by two types of cones: genuine cones exclusively expressing S-opsin pigment (Haverkamp et al., 2005) and cones that coexpress M- and S-opsins along a dorsoventral gradient (Applebury et al., 2000). Functionally, cones in the ventral retina are overwhelmingly driven by $\mathrm{S}$-opsin which has a peak sensitivity at $360 \mathrm{~nm}$, whereas cones in the dorsal retina are strongly driven by M-opsin with peak sensitivity at $510 \mathrm{~nm}$ (Fig. 9A; Nikonov et al., 2006; Wang et al., 2011; Baden et al., 2013; Chang et al., 2013), providing mice with the ability to make dichromatic color discriminations (Jacobs et al., 2004). In the experimental setup we used in our experiments so far described, the overhead LED has a peak emission at $505 \mathrm{~nm}$. This wavelength effectively stimulates rhodopsin and M-opsin but it poorly stimulates the S-opsin (Fig. 9A). In addition, this setup has a 2.5:1 ratio of the overhead to side illumination in the chamber, raising a concern that these stimuli may be poorly activating cones. To assess the contribution of S-opsincontaining cones in the ventral retina to TCS, we tested the response of mice to overhead flicker stimulation at a lower wavelength, 405 $\mathrm{nm}$, which effectively drives both rhodopsin and M-opsin as well as S-opsin (Fig. 9A). We estimated the photoisomerization rate of rods and those of cones that exclusively express M-opsin ("pure M-cones") or S-opsin ("pure S-cones") using the respective end-on collecting areas (see Materials and Methods). This approach allows us to compare the relative activation of rods and cones (before bleaching) in response to light stimulation of 405 and $505 \mathrm{~nm}$ wavelengths at different intensities (Fig. 9B).

The photoisomerization rates of cones coexpressing different proportions of $\mathrm{M}$ - and S-opsin fall within the range delimited by the pure $\mathrm{M}$ - and S-cones (Fig. 9B). For example, a $405 \mathrm{~nm}$ stimuli eliciting 1000 photoisomerizations/s in rods will produce $\sim 500$ photoisomerizations in pure S-cones and 900 photoisomerizations/s in pure M-cones. For cones coexpressing $\mathrm{M}$ - and S-opsin the photoisomerization rates would fall in the range between 500 and 900 photoisomerizations/s, dependent on the proportions of $\mathrm{M}$ - and S-opsin being expressed.

We measured TCS of WT mice to $405 \mathrm{~nm}$ stimuli over a range of intensities that ranged from 300 to $\sim 2000$ rod photoisomerizations/s, the range where cone contributions with $505 \mathrm{~nm}$ stimuli are first observed in the G1 mouse (Fig. 7). In response to $6 \mathrm{~Hz}$ flicker, TCS remained relatively constant for both 405 and 505 nm stimuli (Fig. 9C), whereas TCS to $21 \mathrm{~Hz}$ flicker exhibited a non-monotonic relationship with photoisomerization rates (Fig. 9D). The similarity in TCS values measured with 405 and $505 \mathrm{~nm}$ stimuli at both 6 and $21 \mathrm{~Hz}$ suggests that activation of the S-expressing cones (range 100-1000 photoisomerizations/s; Fig. $9 B$ ) does not dramatically contribute to TCS when M-cones are similarly coactivated. Future studies are required with light stimuli of low wavelengths to fully characterize the role of S-opsin in conditions when M-opsin in cones is weakly activated.

\section{Similar TCS in G2 and G2 KO mice}

A mouse model with a complete knock-out of the GNAT2 gene (G2 KO) has recently been produced (Ronning et al., 2018). The G2 KO mouse is bred on a C57BL/6J background, does not present obvious retinal degeneration and, unlike G2 (cpfl3) mice [GNAT2 ${ }^{\text {cpfl3 }}$ line bred onto the C57BL/6J (black) background], does not respond to intense light flashes. We compared TCS of $\mathrm{G} 2$ (cpfl3) to that of G2 KO mice to confirm that cone activity is not driving TCS in G2 mice. We tested the responses to low (6 $\mathrm{Hz}$ ) and high $(21 \mathrm{~Hz})$ to $505 \mathrm{~nm}$ flicker because they represent the most salient features of the responses in G2 mice. The plots of TCS as a function of retinal irradiance for G2 and G2 KO mice overlap closely (Fig. 10), confirming that cone activity does not contribute significantly to the responses of G2 mice and that both lines of mice can be used interchangeably within the experimental conditions of our studies.

\section{Discussion}

In this study, we show that, in daylight conditions, rod-driven vision in G2 mice exhibits high sensitivity to high temporal frequencies, but not to low temporal frequencies. Our data also suggest that, in wild-type mice, cone-driven responses supplement the loss in rod-driven sensitivity to slow temporal variations. Furthermore, Cx36-independent rod pathways play a critical functional role in extending the dynamic range of roddriven vision. These results provide new insights to our understanding of the rod and cone-driven contributions to TCS during the mesopic transition.

\section{Validity of our models}

Here, we used transgenic mouse models to isolate Cx36independent rod pathways. We detected desensitized G2 cone responses with intense irradiance levels $>10^{5} \mathrm{ph} / \mathrm{s} / \mu \mathrm{m}^{2}$ (Fig. 3), similar to that reported by others (Chang et al., 2006; Allen et al., 2010; Brown et al., 2011). However, the responses of desensitized cones are unlikely to be contributing significantly to TCS in our experiments, as these intense light levels $\left(>10^{5} \mathrm{ph} / \mathrm{s} / \mu \mathrm{m}^{2}\right)$ are 4to 10 -fold brighter than the upper limit of our behavioral studies. Additionally, we also show that TCS in both G2 mice and in the recently developed GNAT2 knock-out mice (Ronning et al., 2018) decline at the brighter intensities used in this study, as is 

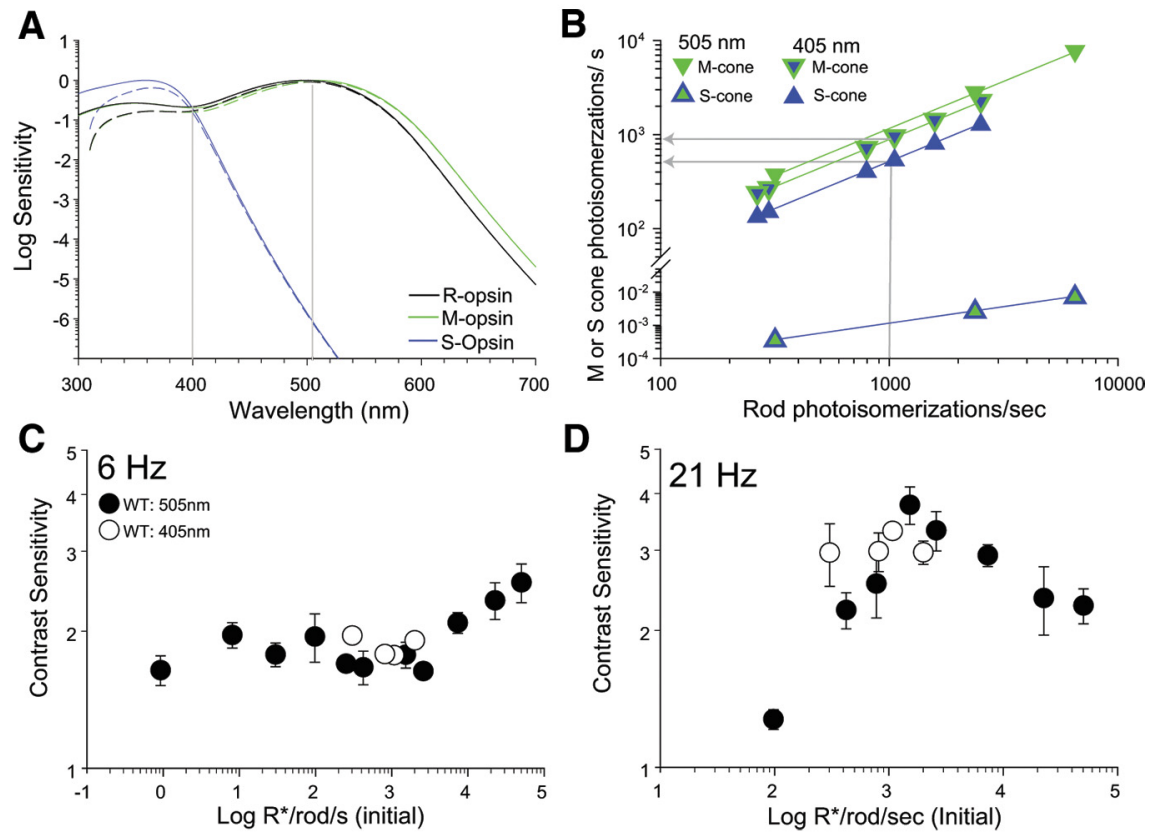

Figure 9. Activation of S-opsin-expressing cones does not contribute significantly to TCS when coactivated with M-opsinexpressing cones. $\boldsymbol{A}$, Normalized sensitivity for rhodopsin (R-opsin), M-opsin, and S-opsin plotted as a function of stimulus wavelength. Fits to mouse pigments were computed according to Lucas et al. (2014) using the Govardovskii nomograms (Govardovskii et al., 2000). Sensitivity after accounting for media losses (Jacobs et al., 2004) is shown with dashed lines. B, Estimated photoisomerization rates in pure M-opsin (green edge symbols) or S-opsin (blue edge symbols) -expressing cones plotted as a function of rod photoisomerization rates for $405 \mathrm{~nm}$ (filled blue symbols) and $505 \mathrm{~nm}$ (filled green symbols) narrowband stimuli (for details of calculations, see Materials and Methods). Photoisomerization rates for cones coexpressing M- and S-opsin at a given wavelength fall within the range delimited by the pure cones (gray arrows; see text for details). C, D, TCS to 405 and $505 \mathrm{~nm}$ plotted as a function of initial (before bleach) rod photoisomerization rates for $(C) 6 \mathrm{~Hz}$ and (D) $21 \mathrm{~Hz}$. TCS to $505 \mathrm{~nm}$ is same as in Figure 7 after converting retinal irradiance to photoisomerizations/s in rods. Symbols represent mean $\pm S D, n=4-11$ mice for $505 \mathrm{~nm}$ and $n=$ 4 mice for $405 \mathrm{~nm}$.
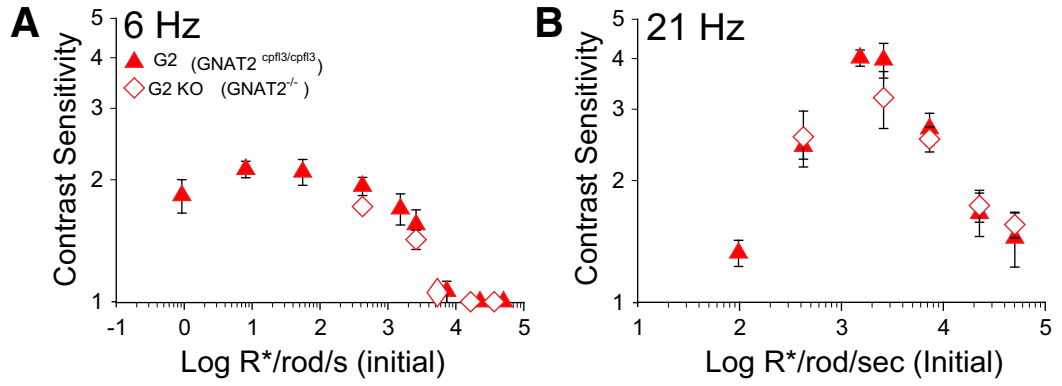

Figure 10. Similar TCS in $\mathrm{G} 2$ and $\mathrm{G} 2 \mathrm{KO}$ mice. $A, B, \mathrm{TCS}$ of $\mathrm{G} 2$ and $\mathrm{G} 2 \mathrm{~K} 0$ mice in response to $505 \mathrm{~nm}$ stimuli plotted as a function of initial (before bleach) rod photoisomerizations in response to $(\boldsymbol{A}) 6 \mathrm{~Hz}$ and $(\boldsymbol{B}) 21 \mathrm{~Hz}$. TCS of G2 mice is same as in Figure 7 after converting retinal irradiance to photoisomerizations/s in rods. TCS of G2 and G2 KO mice matched closely, suggesting that any residual cone function in G2 mice does not alter their TCS. Symbols represent mean \pm SD; $n=3-9$ for G2 mice and $n=4$ for G2KO mice. Note: data points for G2 K0 mice were shifted slightly along the $x$-axis for clarity.

expected for saturation of rod-driven responses (Figs. 4, 10). Together, this suggests that the G2 mouse was an appropriate model to study rod responses under the conditions used in this study.

Electrophysiological recordings support the notion that darkadapted G2 cones have normal dark current and receive input from rods by way of Cx36 gap junctions (A. Sampath, personal communication, November 2018), which is consistent with viable Cx36-dependent secondary pathways in G2 mice. Additionally, we show that G2 and G2::Cx36 mice exhibit normal learning of our operant behavior assay and normal TCS at mesopic light levels (Fig. 6A) suggesting that removal of $\mathrm{Cx} 36$, which is widely expressed in the CNS (Belluardo et al., 2000; Condorelli et al., 2000; Rash et al., 2000; Feigenspan et al., 2001; Degen et al., 2004; Frisch et al., 2005; Zlomuzica et al., 2012), does not negatively impact the animals' behavior for this task.

Last, it is important to note that there are differences in rodent and primate visual systems. A recent study comparing electrophysiological recordings in mouse and primate suggest that (1) primate rods may saturate at lower light levels than mouse rods; and (2) the primary rod pathway is the dominate circuit for roddriven signals in primate, whereas there are more significant contributions by the secondary and/or tertiary rod pathways in mouse (Grimes et al., 2018b). However, it is possible that there are more significant contributions of tertiary rod pathways in primates after a prolonged period of light adaptation.

\section{Cx36-independent rod pathways can relay rod-driven TCS to high temporal frequencies in mesopic light conditions} Here, we found that rod-driven TCS to fast, mesopic light variations does not require $\mathrm{Cx} 36$-dependent rod pathways as previously proposed (Sharpe and Stockman, 1999), but rather that Cx36independent rod pathways are sufficient to mediate this role (Brown et al., 2011). While these results are in line with the observation that secondary pathways play a minimal role in primate vision (Grimes et al., 2018b), they are seemingly at odds with electrophysiological studies in mouse retina which indicate significant secondary rod pathway contribution under mesopic illumination (Grimes et al., 2014; Ke et al., 2014). One possible explanation for the observed differences may be methodological, arising from the differences in the time of exposure to mesopic illumination in the respective studies. Unlike the physiological studies, our behavioral studies were performed following prolonged periods of exposure to light which is known to decrease the coupling strength of $\mathrm{Cx} 36$ gap junctions in the outer retina of mice (Ribelayga et al., 2008; O’Brien et al., 2012; Li et al., 2013; O’Brien, 2014; Jin et al., 2015; Zhang et al., 2015). Thus, the Cx36-dependent secondary rod pathways may be active at scotopic levels, and thereby optimized for signaling brief flashes presented in dim lights rather than during steady mesopic illumination.

Cx36-independent rod pathways include the tertiary rod pathway and the OFF branch of the primary rod pathway. The primary rod pathway has high gain to detect single photons in dim, scotopic light conditions (Barlow et al., 1971; Dunn et al., 2006), but also has the ability to adjust to brighter, mesopic light conditions, by reducing its gain and allowing sensitivity to con- 
trast to be maintained (Dunn and Rieke, 2008; Jarsky et al., 2011; Oesch and Diamond, 2011; Ke et al., 2014; Grimes et al., 2018a). The dynamic range of the primary pathway has been shown to extend up to $250-300 \mathrm{R} * / \mathrm{rod} / \mathrm{s}$ (Ke et al., 2014; Grimes et al., 2018b), although we observed rod-driven TCS at much brighter light levels (up to $10^{4} \mathrm{ph} / \mathrm{s} / \mu \mathrm{m}^{2}$ ). This suggests that TCS at higher irradiance levels may be mediated via the tertiary pathway and not by the OFF branch of the primary pathway. However, we cannot rule out the possibility that the dynamic range of the primary pathway is limited during electrophysiological recordings (Grimes et al., 2018b) due to experimental differences in light-adaptation or absence of a viable pigment epithelium.

Interestingly, as irradiance levels rose through the mesopic range, G2 and G2::Cx36 mice exhibited a relative loss in TCS to slow but not to fast temporal frequencies (Figs. 4, 6). Several candidate mechanisms can be proposed to explain the differential loss in TCS to slow but not to fast temporal frequencies via the Cx36-independent pathways. One possibility is that low and high-frequency information are relayed by distinct rod pathways, wherein the channel conveying lower frequencies (up to $\sim 10 \mathrm{~Hz}$ ) saturates at relatively lower irradiance levels than the channel conveying higher frequencies $(>10 \mathrm{~Hz})$. In this case, low temporal frequency information may be relayed via the primary rod pathway thought to saturate $\sim 300 \mathrm{R}^{\star} / \mathrm{rod} / \mathrm{s}$ (Ke et al., 2014; Grimes et al., 2018b). In contrast, high temporal frequency information could be relayed via direct rod contacts to transient type $3 a$ and type $3 \mathrm{~b}$ OFF bipolar cells of the tertiary rod pathway (Ichinose and Hellmer, 2016). A second candidate mechanism that could explain the frequency-dependent loss in TCS is a selective attenuation of low temporal frequencies by destructive interference of signals converging along two different rod pathways with different speeds of transmission. Such mechanisms have been proposed for interactions between rod pathways in scotopic lights (Sharpe et al., 1989), or between rod and cone pathways in mesopic lights (MacLeod, 1972). Further experiments are required to determine the relative contributions of the two Cx36-independent rod pathways to TCS as a function of retinal irradiance levels and temporal frequency.

\section{Rod driven TCS at bright mesopic lights and high temporal frequencies develops gradually over time}

Rod-driven TCS to high frequencies and bright mesopic lights develops gradually, over a time period of $\sim 30-40 \mathrm{~min}$ (Fig. 5). A similar, gradual recovery in rod responses was recently observed with ganglion cell recordings ex vivo and with dLGN recordings in vivo (Tikidji-Hamburyan et al., 2017). Our findings expand these data to behavioral phenomena, by demonstrating that this time-dependent feature of rod adaptation is observed at the level of perceptual vision. Although the exact mechanisms that underlie the slow time course of rod adaptation at bright lights are still unclear, it has been hypothesized that this could depend on lightdependent changes in the regulation of the phototransduction cascade, resulting in gain reduction and preventing saturation (Tikidji-Hamburyan et al., 2017). One such mechanism is the irradiance-dependent translocation of phototransduction proteins, such as transducin, as these translocations occur at similar light levels $\left(>4 \times 10^{3} \mathrm{R}^{\star} / \mathrm{rod} / \mathrm{s}\right)$ and a similar time course $(\sim 30$ min; Sokolov et al., 2002; Calvert et al., 2006; Lobanova et al., 2007; Slepak and Hurley, 2008). Another contributing factor to the time-dependent rod adaptation to bright lights is likely a form of "bleaching adaptation" similar to what occurs in cones (Burkhardt, 1994), and the response recovery rate correlates with the rate of rhodopsin bleaching (Tikidji-Hamburyan et al., 2017).
Thus, it appears that rods can avoid saturation to relay TCS at high mesopic light levels by means of a time-dependent lightadaptation mechanism.

\section{The mesopic range shifts with temporal frequency}

Comparison of TCS in WT, G2, and G1 mice suggests a lower limit for the mesopic range of $\sim 10^{2} \mathrm{R}^{\star} / \mathrm{rod} / \mathrm{s}$ in response low (6 $\mathrm{Hz}$ ) temporal frequency flicker (Figs. 7, 8). This value agrees closely with the lower mesopic limit to incremental flashes determined with a running wheel assay (Naarendorp et al., 2010). However, we found that the value of this lower limit is not absolute and depends on the frequency of the flicker. At high temporal frequencies $(21 \mathrm{~Hz})$ the lower limit of the mesopic range increased to $\sim 10^{3} \mathrm{ph} / \mathrm{s} / \mu \mathrm{m}^{2}$. Remarkably, over much of the mesopic range, rods alone (in G2 mice) can mediate normal TCS levels (in WT mice), whereas cones alone (in G1 mice) cannot mediate normal TCS. Together, these findings suggest that rodand cone-driven signals do not simply add to produce the mesopic visual thresholds (Buck, 2014). These results indicate that rods are essential for high temporal frequency vision at bright mesopic light levels and highlights the complexity of the mesopic transition in the vertebrate visual system.

\section{References}

Abd-El-Barr MM, Pennesi ME, Saszik SM, Barrow AJ, Lem J, Bramblett DE, Paul DL, Frishman LJ, Wu SM (2009) Genetic dissection of rod and cone pathways in the dark-adapted mouse retina. J Neurophysiol 102: 1945-1955.

Allen AE, Lucas RJ (2016) Using silent substitution to track the mesopic transition from rod- to cone-based vision in mice. Invest Ophthalmol Vis Sci 57:276-287.

Allen AE, Cameron MA, Brown TM, Vugler AA, Lucas RJ (2010) Visual responses in mice lacking critical components of all known retinal phototransduction cascades. PLoS One 5:e15063.

Altimus CM, Güler AD, Alam NM, Arman AC, Prusky GT, Sampath AP, Hattar S (2010) Rod photoreceptors drive circadian photoentrainment across a wide range of light intensities. Nat Neurosci 13:1107-1112.

Applebury ML, Antoch MP, Baxter LC, Chun LL, Falk JD, Farhangfar F, Kage K, Krzystolik MG, Lyass LA, Robbins JT (2000) The murine cone photoreceptor: a single cone type expresses both $\mathrm{S}$ and $\mathrm{M}$ opsins with retinal spatial patterning. Neuron 27:513-523.

Baden T, Schubert T, Chang L, Wei T, Zaichuk M, Wissinger B, Euler T (2013) A tale of two retinal domains: near-optimal sampling of achromatic contrasts in natural scenes through asymmetric photoreceptor distribution. Neuron 80:1206-1217.

Barlow HB, Levick WR, Yoon M (1971) Responses to single quanta of light in retinal ganglion cells of the cat. Vision Res 3:87-101.

Bayley PR, Morgans CW (2007) Rod bipolar cells and horizontal cells form displaced synaptic contacts with rods in the outer nuclear layer of the nob2 retina. J Comp Neurol 500:286-298.

Belluardo N, Mudò G, Trovato-Salinaro A, Le Gurun S, Charollais A, SerreBeinier V, Amato G, Haefliger JA, Meda P, Condorelli DF (2000) Expression of connexin 36 in the adult and developing rat brain. Brain Res 865:121-138.

Berson DM, Dunn FA, Takao M (2002) Phototransduction by retinal ganglion cells that set the circadian clock. Science 295:1070-1073.

Bloomfield SA, Dacheux RF (2001) Rod vision: pathways and processing in the mammalian retina. Prog Retin Eye Res 20:351-384.

Bloomfield SA, Völgyi B (2009) The diverse functional roles and regulation of neuronal gap junctions in the retina. Nat Rev Neurosci 10:495-506.

Brown TM, Allen AE, Wynne J, Paul DL, Piggins HD, Lucas RJ (2011) Visual responses in the lateral geniculate evoked by $\mathrm{Cx} 36$-independent rod pathways. Vision Res 51:280-287.

Buck S (2014) The interactions of rod and cone signals: pathways and psychophysics. In: The new visual neurosciences (Werner J, Chalupa L, eds), pp 485-497. Cambridge, MA: MIT.

Burkhardt DA (1994) Light adaptation and photopigment bleaching in cone photoreceptors in situ in the retina of the turtle. J Neurosci 14:10911105. 
Bushnell M, Umino Y, Solessio E (2016) A system to measure the pupil response to steady lights in freely behaving mice. J Neurosci Methods 273:74-85.

Calvert PD, Krasnoperova NV, Lyubarsky AL, Isayama T, Nicoló M, Kosaras B, Wong G, Gannon KS, Margolskee RF, Sidman RL, Pugh EN Jr, Makino CL, Lem J (2000) Phototransduction in transgenic mice after targeted deletion of the rod transducin alpha-subunit. Proc Natl Acad Sci U S A 97:13913-13918.

Calvert PD, Strissel KJ, Schiesser WE, Pugh EN Jr, Arshavsky VY (2006) Light-driven translocation of signaling proteins in vertebrate photoreceptors. Trends Cell Biol 16:560-568.

Chang B, Dacey MS, Hawes NL, Hitchcock PF, Milam AH, Atmaca-Sonmez P, Nusinowitz S, Heckenlively JR (2006) Cone photoreceptor function loss-3, a novel mouse model of achromatopsia due to a mutation in Gnat2. Invest Ophthalmol Vis Sci 47:5017-5021.

Chang L, Breuninger T, Euler T (2013) Chromatic coding from cone-type unselective circuits in the mouse retina. Neuron 77:559-571.

Condorelli DF, Belluardo N, Trovato-Salinaro A, Mudò G (2000) Expression of Cx36 in mammalian neurons. Brain Res Brain Res Rev 32:72-85.

Conner JD (1982) The temporal properties of rod vision. J Physiol 332:139-155.

Conner JD, MacLeod DI (1977) Rod photoreceptors detect rapid flicker. Science 195:698-699.

Cowan CS, Abd-El-Barr M, van der Heijden M, Lo EM, Paul D, Bramblett DE, Lem J, Simons DL, Wu SM (2016) Connexin 36 and rod bipolar cell independent rod pathways drive retinal ganglion cells and optokinetic reflexes. Vision Res 119:99-109.

Deans MR, Völgyi B, Goodenough DA, Bloomfield SA, Paul DL (2002) Connexin 36 is essential for transmission of rod-mediated visual signals in the mammalian retina. Neuron 36:703-712.

Degen J, Meier C, Van Der Giessen RS, Söhl G, Petrasch-Parwez E, Urschel S, Dermietzel R, Schilling K, De Zeeuw CI, Willecke K (2004) Expression pattern of lacZ reporter gene representing connexin 36 in transgenic mice. J Comp Neurol 473:511-525.

DeVries SH, Baylor DA (1995) An alternative pathway for signal flow from rod photoreceptors to ganglion cells in mammalian retina. Proc Natl Acad Sci U S A 92:10658-10662.

Dunn FA, Rieke F (2008) Single-photon absorptions evoke synaptic depression in the retina to extend the operational range of rod vision. Neuron 57:894-904.

Dunn FA, Doan T, Sampath AP, Rieke F (2006) Controlling the gain of rod-mediated signals in the mammalian retina. J Neurosci 26:3959-3970.

Feigenspan A, Teubner B, Willecke K, Weiler R (2001) Expression of neuronal connexin36 in AII amacrine cells of the mammalian retina. J Neurosci 21:230-239.

Field GD, Rieke F (2002) Nonlinear signal transfer from mouse rods to bipolar cells and implications for visual sensitivity. Neuron 34:773-785.

Fortenbach CR, Kessler C, Peinado Allina G, Burns ME (2015) Speeding rod recovery improves temporal resolution in the retina. Vision Res 110: $57-67$.

Frisch C, De Souza-Silva MA, Söhl G, Güldenagel M, Willecke K, Huston JP, Dere E (2005) Stimulus complexity dependent memory impairment and changes in motor performance after deletion of the neuronal gap junction protein connexin36 in mice. Behav Brain Res 157:177-185.

Govardovskii VI, Fyhrquist N, Reuter T, Kuzmin DG, Donner K (2000) In search of the visual pigment template. Vis Neurosci 17:509-528.

Grimes WN, Schwartz GW, Rieke F (2014) The synaptic and circuit mechanisms underlying a change in spatial encoding in the retina. Neuron $82: 460-473$.

Grimes WN, Songco-Aguas A, Rieke F (2018a) Parallel processing of rod and cone signals: retinal function and human perception. Annu Rev Vis Sci 4:123-141.

Grimes WN, Baudin J, Azevedo AW, Rieke F (2018b) Range, routing and kinetics of rod signaling in primate retina. eLife 7:e38281.

Güldenagel M, Ammermüller J, Feigenspan A, Teubner B, Degen J, Söhl G, Willecke K, Weiler R (2001) Visual transmission deficits in mice with targeted disruption of the gap junction gene connexin36. J Neurosci 21: 6036-6044.

Hack I, Peichl L, Brandstätter JH (1999) An alternative pathway for rod signals in the rodent retina: rod photoreceptors, cone bipolar cells, and the localization of glutamate receptors. Proc Natl Acad Sci U S A 96: $14130-14135$.
Hattar S, Liao HW, Takao M, Berson DM, Yau KW (2002) Melanopsincontaining retinal ganglion cells: architecture, projections, and intrinsic photosensitivity. Science 295:1065-1070.

Haverkamp S, Wässle H, Duebel J, Kuner T, Augustine GJ, Feng G, Euler T (2005) The primordial, blue-cone color system of the mouse retina. J Neurosci 25:5438-5445.

Hess RF, Nordby K (1986) Spatial and temporal properties of human rod vision in the achromat. J Physiol 371:387-406.

Ichinose T, Hellmer CB (2016) Differential signalling and glutamate receptor compositions in the OFF bipolar cell types in the mouse retina. J Physiol 594:883-894.

Jacobs GH, Williams GA (2007) Contributions of the mouse UV photopigment to the ERG and to vision. Doc Ophthalmol 115:137-144.

Jacobs GH, Neitz J, Deegan JF 2nd (1991) Retinal receptors in rodents maximally sensitive to ultraviolet light. Nature 353:655-656.

Jacobs GH, Williams GA, Fenwick JA (2004) Influence of cone pigment coexpression on spectral sensitivity and color vision in the mouse. Vision Res 44:1615-1622.

Jarsky T, Cembrowski M, Logan SM, Kath WL, Riecke H, Demb JB, Singer JH (2011) A synaptic mechanism for retinal adaptation to luminance and contrast. J Neurosci 31:11003-11015.

Jin NG, Chuang AZ, Masson PJ, Ribelayga CP (2015) Rod electrical coupling is controlled by a circadian clock and dopamine in mouse retina. J Physiol 593:1597-1631.

Ke JB, Wang YV, Borghuis BG, Cembrowski MS, Riecke H, Kath WL, Demb JB, Singer JH (2014) Adaptation to background light enables contrast coding at rod bipolar cell synapses. Neuron 81:388-401.

LaVail MM (1980) Interaction of environmental light and eye pigmentation with inherited retinal degenerations. Vision Res 20:1173-1177.

Lei B (2012) Rod-driven OFF pathway responses in the distal retina: darkadapted flicker electroretinogram in mouse. PLoS One 7:e43856.

Li H, Zhang Z, Blackburn MR, Wang SW, Ribelayga CP, O'Brien J (2013) Adenosine and dopamine receptors coregulate photoreceptor coupling via gap junction phosphorylation in mouse retina. J Neurosci 33: 3135-3150.

Li W, Chen S, DeVries SH (2010) A fast rod photoreceptor signaling pathway in the mammalian retina. Nat Neurosci 13:414-416.

Lobanova ES, Finkelstein S, Song H, Tsang SH, Chen CK, Sokolov M, Skiba NP, Arshavsky VY (2007) Transducin translocation in rods is triggered by saturation of the GTPase-activating complex. J Neurosci 27:1151-1160.

Lucas RJ, Peirson SN, Berson DM, Brown TM, Cooper HM, Czeisler CA, Figueiro MG, Gamlin PD, Lockley SW, O’Hagan JB, Price LL, Provencio I, Skene DJ, Brainard GC (2014) Measuring and using light in the melanopsin age. Trends Neurosci 37:1-9.

Lyubarsky AL, Daniele LL, Pugh EN Jr (2004) From candelas to photoisomerizations in the mouse eye by rhodopsin bleaching in situ and the light-rearing dependence of the major components of the mouse ERG. Vision Res 44:3235-3251.

MacLeod DI (1972) Rods cancel cones in flicker. Nature 235:173-174.

Macmillan N, Creelman C (2005) Detection theory: a user's guide. New York: Lawrence Erlbaum.

Naarendorp F, Esdaille TM, Banden SM, Andrews-Labenski J, Gross OP, Pugh EN Jr (2010) Dark light, rod saturation, and the absolute and incremental sensitivity of mouse cone vision. J Neurosci 30:12495-12507.

Naash MI, Ripps H, Li S, Goto Y, Peachey NS (1996) Polygenic disease and retinitis pigmentosa: albinism exacerbates photoreceptor degeneration induced by the expression of a mutant opsin in transgenic mice. J Neurosci 16:7853-7858.

Nakatani K, Tamura T, Yau KW (1991) Light adaptation in retinal rods of the rabbit and two other nonprimate mammals. J Gen Physiol 97:413-435.

Nathan J, Reh R, Ankoudinova I, Ankoudinova G, Chang B, Heckenlively J, Hurley JB (2006) Scotopic and photopic visual thresholds and spatial and temporal discrimination evaluated by behavior of mice in a water maze. Photochem Photobiol 82:1489-1494.

Nelson R (1977) Cat cones have rod input: a comparison of the response properties of cones and horizontal cell bodies in the retina of the cat. J Comp Neurol 172:109-135.

Nikonov SS, Kholodenko R, Lem J, Pugh EN Jr (2006) Physiological features of the S- and M-cone photoreceptors of wild-type mice from singlecell recordings. J Gen Physiol 127:359-374.

Nusinowitz S, Ridder WH 3rd, Ramirez J (2007) Temporal response prop- 
erties of the primary and secondary rod-signaling pathways in normal and Gnat2 mutant mice. Exp Eye Res 84:1104-1114.

O’Brien J (2014) The ever-changing electrical synapse. Curr Opin Neurobiol 29:64-72.

O’Brien JJ, Chen X, Macleish PR, O’Brien J, Massey SC (2012) Photoreceptor coupling mediated by connexin 36 in the primate retina. J Neurosci 32:4675-4687.

Oesch NW, Diamond JS (2011) Ribbon synapses compute temporal contrast and encode luminance in retinal rod bipolar cells. Nat Neurosci 14:1555-1561.

Pang JJ, Gao F, Lem J, Bramblett DE, Paul DL, Wu SM (2010) Direct rod input to cone $\mathrm{BCs}$ and direct cone input to rod $\mathrm{BCs}$ challenge the traditional view of mammalian BC circuitry. Proc Natl Acad Sci U S A 107:395-400.

Pang JJ, Gao F, Paul DL, Wu SM (2012) Rod, M-cone and M/S-cone inputs to hyperpolarizing bipolar cells in the mouse retina. J Physiol 590:845-854.

Prusky GT, Alam NM, Beekman S, Douglas RM (2004) Rapid quantification of adult and developing mouse spatial vision using a virtual optomotor system. Invest Ophthalmol Vis Sci 45:4611-4616.

Rapp LM, Williams TP (1980) The role of ocular pigmentation in protecting against retinal light damage. Vision Res 20:1127-1131.

Rash JE, Staines WA, Yasumura T, Patel D, Furman CS, Stelmack GL, Nagy JI (2000) Immunogold evidence that neuronal gap junctions in adult rat brain and spinal cord contain connexin-36 but not connexin-32 or connexin-43. Proc Natl Acad Sci U S A 97:7573-7578.

Ribelayga C, Cao Y, Mangel SC (2008) The circadian clock in the retina controls rod-cone coupling. Neuron 59:790-801.

Ronning KE, Allina GP, Miller EB, Zawadzki RJ, Pugh EN Jr, Herrmann R, Burns ME (2018) Loss of cone function without degeneration in a novel Gnat2 knock-out mouse. Exp Eye Res 171:111-118.

Schneeweis DM, Schnapf JL (1999) The photovoltage of macaque cone photoreceptors: adaptation, noise, and kinetics. J Neurosci 19:1203-1216.

Schroeder MM, Harrison KR, Jaeckel ER, Berger HN, Zhao X, Flannery MP, St Pierre EC, Pateqi N, Jachimska A, Chervenak AP, Wong KY (2018) The roles of rods, cones, and melanopsin in photoresponses of M4 intrinsically photosensitive retinal ganglion cells (ipRGCs) and optokinetic visual behavior. Front Cell Neurosci 12:203.

Sharpe LT, Stockman A (1999) Rod pathways: the importance of seeing nothing. Trends Neurosci 22:497-504.

Sharpe LT, Stockman A, MacLeod DI (1989) Rod flicker perception: scotopic duality, phase lags and destructive interference. Vision Res 29:1539-1559.

Slepak VZ, Hurley JB (2008) Mechanism of light-induced translocation of arrestin and transducin in photoreceptors: interaction-restricted diffusion. IUBMB Life 60:2-9.

Sokolov M, Lyubarsky AL, Strissel KJ, Savchenko AB, Govardovskii VI, Pugh EN Jr, Arshavsky VY (2002) Massive light-driven translocation of transducin between the two major compartments of rod cells: a novel mechanism of light adaptation. Neuron 34:95-106.

Soucy E, Wang Y, Nirenberg S, Nathans J, Meister M (1998) A novel signal- ing pathway from rod photoreceptors to ganglion cells in mammalian retina. Neuron 21:481-493.

Tikidji-Hamburyan A, Reinhard K, Storchi R, Dietter J, Seitter H, Davis KE, Idrees S, Mutter M, Walmsley L, Bedford RA, Ueffing M, Ala-Laurila P, Brown TM, Lucas RJ, Münch TA (2017) Rods progressively escape saturation to drive visual responses in daylight conditions. Nat Commun 8:1813.

Tsukamoto Y, Omi N (2014) Some OFF bipolar cell types make contact with both rods and cones in macaque and mouse retinas. Front Neuroanat 8:105.

Tsukamoto Y, Morigiwa K, Ueda M, Sterling P (2001) Microcircuits for night vision in mouse retina. J Neurosci 21:8616-8623.

Tsukamoto Y, Morigiwa K, Ishii M, Takao M, Iwatsuki K, Nakanishi S, Fukuda Y (2007) A novel connection between rods and ON cone bipolar cells revealed by ectopic metabotropic glutamate receptor 7 (mGluR7) in mGluR6-deficient mouse retinas. J Neurosci 27:6261-6267.

Umino Y, Frio B, Abbasi M, Barlow R (2006) A two-alternative, forced choice method for assessing mouse vision. Adv Exp Med Biol 572:169-172.

Umino Y, Solessio E, Barlow RB (2008) Speed, spatial, and temporal tuning of rod and cone vision in mouse. J Neurosci 28:189-198.

Umino Y, Pasquale R, Solessio E (2018) Visual temporal contrast sensitivity in the behaving mouse shares fundamental properties with human psychophysics. eNeuro 5:ENEURO.0181-18.2018.

Umino Y, Guo Y, Chen CK, Pasquale R, Solessio E (2019) Rod photoresponse kinetics limit temporal contrast sensitivity in mesopic vision. J Neurosci 39:3041-3056.

Völgyi B, Deans MR, Paul DL, Bloomfield SA (2004) Convergence and segregation of the multiple rod pathways in mammalian retina. J Neurosci 24:11182-11192.

Walraven J, Enroth-Cugell C, Hood DC, MacLeod DI, Schnapf JL (1990) The control of visual sensitivity: receptoral and postreceptoral processes. In: Visual perception: the neurophysiological foundations (Spillmann L, Werner JS, eds). San Diego: Academic.

Wang YV, Weick M, Demb JB (2011) Spectral and temporal sensitivity of cone-mediated responses in mouse retinal ganglion cells. J Neurosci 31:7670-7681.

Yin L, Smith RG, Sterling P, Brainard DH (2006) Chromatic properties of horizontal and ganglion cell responses follow a dual gradient in cone opsin expression. J Neurosci 26:12351-12361.

Zhang Z, Li H, Liu X, O’Brien J, Ribelayga CP (2015) Circadian clock control of connexin 36 phosphorylation in retinal photoreceptors of the CBA/ CaJ mouse strain. Vis Neurosci 32:E009.

Zhu X, Li A, Brown B, Weiss ER, Osawa S, Craft CM (2002) Mouse cone arrestin expression pattern: light induced translocation in cone photoreceptors. Mol Vis 8:462-471.

Zlomuzica A, Viggiano D, Degen J, Binder S, Ruocco LA, Sadile AG, Willecke $\mathrm{K}$, Huston JP, Dere E (2012) Behavioral alterations and changes in $\mathrm{Ca} /$ calmodulin kinase II levels in the striatum of connexin36 deficient mice. Behav Brain Res 226:293-300. 